Illinois State University

ISU ReD: Research and eData

Theses and Dissertations

3-4-2021

\title{
Investigating Family Communication Patterns And Parent-Child Relationships In Homeschooling Experiences
}

Victoria Eleanor Padilla

Illinois State University, vepadilla17@gmail.com

Follow this and additional works at: https://ir.library.illinoisstate.edu/etd

Part of the Communication Commons

\section{Recommended Citation}

Padilla, Victoria Eleanor, "Investigating Family Communication Patterns And Parent-Child Relationships In Homeschooling Experiences" (2021). Theses and Dissertations. 1398.

https://ir.library.illinoisstate.edu/etd/1398

This Thesis is brought to you for free and open access by ISU ReD: Research and eData. It has been accepted for inclusion in Theses and Dissertations by an authorized administrator of ISU ReD: Research and eData. For more information, please contact ISUReD@ilstu.edu. 


\section{INVESTIGATING FAMILY COMMUNICATION PATTERNS AND PARENT-CHILD RELATIONSHIPS IN HOMESCHOOLING EXPERIENCES}

\section{VICTORIA E. PADILLA}

\section{Pages}

The purpose of this study is to collect quantitative data from children and parents regarding their homeschool experiences. Data are explored through the lens of instructional communication, family communication, parent-child relational satisfaction, and parent-child closeness. The present study examined the connections between education and family when learning takes place at home. Findings explain the relationship between parents and children after homeschooling has ended and future research is suggested for homeschooling, instructional communication, and family communication.

KEYWORDS: homeschool; instructional approaches; family relationships; family communication patterns; parent-child relational satisfaction; parent-child closeness 


\title{
INVESTIGATING FAMILY COMMUNICATION PATTERNS AND PARENT-CHILD RELATIONSHIPS IN HOMESCHOOLING EXPERIENCES
}

VICTORIA E. PADILLA

\author{
A Thesis Submitted in Partial \\ Fulfillment of the Requirements \\ for the Degree of \\ MASTER OF SCIENCE \\ School of Communication \\ ILLINOIS STATE UNIVERSITY
}


Copyright 2021 Victoria E. Padilla 


\section{INVESTIGATING FAMILY COMMUNICATION PATTERNS AND PARENT-CHILD RELATIONSHIPS IN HOMESCHOOLING EXPERIENCES}

VICTORIA E. PADILLA

COMMITTEE MEMBERS:

Kevin R. Meyer, Chair

Cheri J. Simonds

Stephen K. Hunt 


\section{ACKNOWLEDGMENTS}

First and foremost, this thesis would not exist without the guidance of Dr. Kevin Meyer, my thesis chair. Dr. Meyer, thank you for being my mentor throughout graduate school, from enrollment into the program through the very end as my committee chair. Your perspective, questions, suggestions, and guidance truly made this thesis possible. Thank you for believing in my concept when I came to you with a jumbled, hand-drawn idea web, and helping me shape it into an interesting, relevant, and timely independent study and thesis. Thank you.

Special thanks to Dr. Cheri Simonds and Dr. Stephen Hunt, my thesis committee. Your perspective, comments, and guidance helped guide this paper and allowed me to take ownership of something I am proud of. Your constructive feedback and guidance contributed greatly to this thesis.

I want to give special mention to Dr. Samantha Shebib. Thank you for taking the time to have a phone call, and subsequent emails, with a graduate student you never met. Your guidance and your own research inspired me to really dive deep and dig in. The resources and information you provided truly helped kickstart and guide my thesis. I hope you enjoy this, because after (virtually) meeting you and conversing, I hope to make you proud.

Thank you to my ROE \# 17 work family, I am so grateful for the team of inspiring and supportive individuals I work with. I appreciate your sponsorship and encouragement of my continued education. I am excited that my research on homeschooling will allow us to look at communication within education from a new perspective.

To my friends, you are the best. This would not be possible without the support of the amazing tribe of women at my side. Thank you for the pep talks, FaceTime yoga, Marco Polos, 
and the lunch dates-you ladies are the real MVPs! I don't know how I would have kept my sanity intact without your support.

To my mom, thank you for your constant excitement around graduate school and this thesis. You inspire me to push through, and I needed your tough-love "just get it done" mindset more than once throughout this journey.

Josh, my awesome husband, thank you. In school, and in life, thank you for being my constant source of love and support. Thank you for listening, understanding, making me laugh, and always being at my side. Thank you for holding down the fort while I was in class or writing, and sometimes surprising me with brownies and ice-cream after a three-hour night class (after a full work day). I love you more than you know and am looking forward to some guiltfree tv binging and hanging out.

Finally, I cannot go without a shout out to my boys, Roku, Bumi, and Appa. Although dogs cannot read, thank you for your support. I was never without one of my boys at my feet as I wrote, and you always knew the perfect time to nudge my arm from typing to take quick snuggle break.

V. E. P. 


\section{CONTENTS}

$\begin{array}{lll}\text { Page } & \\ \end{array}$

ACKNOWLEDGMENTS

CONTENTS

TABLES

CHAPTER I: REVIEW OF LITERATURE 1

$\begin{array}{ll}\text { Choosing Homeschooling } & 4\end{array}$

Family Communication Patterns $\quad 5$

$\begin{array}{ll}\text { Protective } & 8\end{array}$

$\begin{array}{ll}\text { Consensual } & 9\end{array}$

$\begin{array}{ll}\text { Pluralistic } & 10\end{array}$

$\begin{array}{ll}\text { Laissez-Faire } & 11\end{array}$

$\begin{array}{ll}\text { Perceptions of Homeschooling } & 12\end{array}$

$\begin{array}{ll}\text { Instructional Communication } & 16\end{array}$

$\begin{array}{ll}\text { Relational Satisfaction } & 22\end{array}$

$\begin{array}{ll}\text { Closeness } & 25\end{array}$

$\begin{array}{ll}\text { Conclusion } & 28\end{array}$

$\begin{array}{ll}\text { CHAPTER II: METHODS } & 30\end{array}$

$\begin{array}{ll}\text { Participants } & 30\end{array}$

$\begin{array}{ll}\text { Procedures } & 32\end{array}$

$\begin{array}{ll}\text { Measures } & 32\end{array}$

Homeschooling Instructional Approaches $\quad 32$

Communication and Conformity Orientation 35 
Parent-Child Relational Satisfaction 36

$\begin{array}{ll}\text { Parent-Child Closeness } & 39\end{array}$

Perceptions of Homeschooling $\quad 40$

$\begin{array}{ll}\text { Data Analysis } & 41\end{array}$

CHAPTER III: RESULTS

Regression Models for Instructional Approach $\quad 44$

Regression Models for Relational Satisfaction $\quad 48$

Regression Models for Parent-Child Closeness 53

Results Summary $\quad 59$

CHAPTER IV: DISCUSSION

$\begin{array}{ll}\text { Summary of Findings } & 61\end{array}$

$\begin{array}{ll}\text { Implications } & 67\end{array}$

$\begin{array}{ll}\text { Practical Implications } & 67\end{array}$

$\begin{array}{ll}\text { Theoretical Implications } & 70\end{array}$

$\begin{array}{ll}\text { Limitations } & 75\end{array}$

$\begin{array}{ll}\text { Suggestions for Future Research } & 78\end{array}$

$\begin{array}{lr}\text { Conclusion } & 80\end{array}$

REFERENCES $\quad 82$

$\begin{array}{ll}\text { APPENDIX: SURVEY INSTRUMENT } & 90\end{array}$ 


\section{TABLES}

Table

Page

1. Family Communication Patterns

2. Factor Loadings for Student Homeschooling Instructional Approach

3. Factor Loadings for Parent Homeschooling Instructional Approach

4. Factor Loadings for Student Relational Satisfaction

5. Factor Loadings for Parent Relational Satisfaction

6. Factor Loadings for Student Relational Closeness

7. Factor Loadings for Parent Relational Closeness

8. Beta Weights for Student RFCP Predicting Instructional Approach

9. Beta Weights for Parent RFCP Predicting Instructional Approach

10. Beta Weights for Student ECOS Predicting Instructional Approach

11. Beta Weights for Parent ECOS Predicting Instructional Approach

12. Descriptive Statistics for Relational Satisfaction

13. Beta Weights for Instructional Approach Predicting Student Relational Satisfaction

14. Beta Weights for Instructional Approach Predicting Parent Relational Satisfaction

15. Beta Weights for Student RFCP Predicting Relational Satisfaction

16. Beta Weights for Parent RFCP Predicting Relational Satisfaction

17. Beta Weights for Student ECOS Predicting Relational Satisfaction

18. Beta Weights for Parent ECOS Predicting Relational Satisfaction

19. Descriptive Statistics for Relational Closeness

20. Beta Weights for Instructional Approach Predicting Student Relational Closeness 
22. Beta Weights for Student RFCP Predicting Relational Closeness

23. Beta Weights for Parent RFCP Predicting Relational Closeness

24. Beta Weights for Student ECOS Predicting Relational Closeness

25. Beta Weights for Parent ECOS Predicting Relational Closeness

26. Correlations among Scales for Student Reported Data

27. Correlations among Scales for Parent Reported Data 


\section{CHAPTER I: REVIEW OF LITERATURE}

In the current climate of COVID-19, communication in homeschooling environments is more relevant than ever to explore. There is a gap in homeschooling literature because most communication research assumes an unchanging vision of school and education. The role of parent as instructor, and child as student needs to be examined as the current pandemic has forced families into remote learning or homeschooling, leaving many families feeling overwhelmed and unprepared. For some families, remote learning provides insight into homeschooling, although the two are not the same.

Remote learning is when curriculum is provided by the student's local school district, and teachers provide instruction through online platforms such as Zoom, Google Classroom, or through a third-party educational provider. Homeschooling is when a family decides not to participate in the curriculum provided by the local district, and take full responsibility for the planning, assessment, and education of the children in their home. While the focus of this study is specifically on homeschooling, it is possible that the findings could have implications on remote learning settings as well. The purpose of this study is to provide meaningful insight into the existing relational patterns within homeschooling families, but ultimately the goal is to provide meaningful guidance for families who are considering homeschooling. The dynamic of families, relationships, and instruction changes greatly when the classroom is the kitchen table.

While homeschool can be provided by any guardian, for sake of simplicity, the term parent will be used to describe any guardian providing homeschool instruction to a child within the home. Current literature on family communication assumes that parents play the role of parent and children play the role of child. However, in homeschooling, parents and children play multiple roles and interchange different hats throughout the day. Parents become instructors and 
children become students. To date, family communication research has not taken into consideration that sometimes the home is also a place of instruction.

Homeschooling refers to home-based education, wherein the parent serves in the role of the teacher and their child is the student. It is the practice of parents removing their children from the traditional school structure and assuming authority and responsibility for their child's education. Communication changes when children and parents spend not only family time together, but also school time. It changes when a parent not only has to parent their child, but also teach them math and science. It changes when children become dependent on their parents for their education. Current literature in the fields of family, instructional, relationship satisfaction, and closeness communication assume a traditional, public school, 8:00 A.M.-3:00 P.M. schedule where students leave the home to learn.

In today's world, homeschooling can still mean textbooks at the kitchen table with mom as the teacher, or it can mean logging into an online platform to complete learning modules and quizzes. Homeschooling can also be a hybrid of the two, or any other creation based on the family's definition of appropriate education. Most states regulate homeschool very loosely and essentially allow families to educate children on an honor system. According to the Home School Legal Defense Agency, most states in the United States require low-to-no regulation for homeschool families (HSDLA, 2020). For these low-to-no regulation states, like Illinois, for example, parents have complete flexibility in the manner, methods, and timeframe of their educational program (105 ILCS S 5/26-1). Homeschooling is appealing to some families due to the control of content and delivery, but the decision to initiate homeschool can be intentional or reactional. 
Intentional homeschooling describes families that carefully selected homeschooling as the best educational option for their children. Generally, this family is proactive and makes education part of their lifestyle and was agreed upon and discussed in detail by all invested guardians. Reactional homeschooling refers to families that made the decision to homeschool based on a response to an upsetting situation such as truancy, poor grades, or bullying. Reactional families did zero, or very brief, research before removing their child from public school (Padilla, 2020). While reactional families may become intentional over time, this family did not initially plan to homeschool. Either intentional or reactional, homeschooling is getting more attention in research and popular media and is becoming more common as an educational option than it was once.

In the realm of communication, homeschool offers an interesting setting for instructional communication, family communication, and relational satisfaction and closeness behaviors. Regarding instructional communication, parents can determine how to educate their child. They can provide a rigorous, structured environment, be completely hands-off, or somewhere in between. The communicative style they use to instruct their child can impact their relationship with their child when the school day is over and they are just a parent, and not a teacher. Even more interesting would be how families that homeschooled report about their relationships after the fact, post-graduation. Does the homeschool instructional approach influence their relationship? Do they feel closer to their parent, or further apart? Are they satisfied with the relationship? The homeschooling setting promises to be a robust environment for advancing communication theory. 


\section{Choosing Homeschooling}

The United States has about 2.5 million homeschool students in grades K-12, which represents approximately $4 \%$ of school-aged children. The number of homeschoolers per year has been increasing by about $2.5 \%$ each year for the last 10 years (Ray, 2020). The increasing popularity and coverage of homeschooling in mainstream media means more families from different backgrounds are learning about and trying homeschooling. Previous studies have determined that while parents turn to homeschooling for a wide variety of reasons, they can be lumped into one of four broad categories: dissatisfaction with public school, academic and pedagogical concerns, religious values, or family needs (Brown, 1997; Endress, 2011). It is a diverse group with differing and overlapping motivations (Collom, 2005). Though the motivators can vary greatly, they can usually fall into two broader categories: empirical or ideological.

While the initial decision to homeschool can be intentional or reactional, the deeper meaning behind their decision is either empirical or ideological. According to Brewer and Lubienski (2017) and their study on homeschooling in the United States, these two broad categories can be defined as "(1) empirical-claims of greater efficiency, effectiveness, or pedagogical appropriateness; and (2) ideological-often informed by a religious or political disposition" (p. 22). The decision to homeschool not only affects the education of the child, but the communication patterns within the home. Families can have many reasons for homeschooling from faith, to careers, to learning abilities — and each one of those reasons will impact the relationship and family communication patterns differently. Stereotypically, the homeschooling families that fall under the ideological category, would be thought of as highly religious, but newer studies are discovering that modern families are attracted to it because traditional schools are not liberal enough (Romanowski, 2006). Regardless of what the typical 
homeschooling family looks like, the role of parent as educator and child as student is the common thread. Once a family has decided to homeschool, the next step is to determine the level of involvement and time they can commit to achieve the desired academic outcomes.

\section{Family Communication Patterns}

In homeschool settings, family communication plays a large role because generally, parents are teaching their children. Parents that also fill the role of educator may communicate differently with their children and those communication patterns could impact their relationship. Parents as educators makes logical sense because family members are supposed to nurture one another and provide support (Koerner \& Fitzpatrick, 2002a). Family relationship type and communication style impact how members interact with the world. To illustrate family communication patterns researchers created, and then fine-tuned a model to help demonstrate consistent and expected ways in which families communicate within themselves (Shebib, 2020). There are two axes of family communication patterns: conversation orientation and conformity orientation. Where those two orientations intersect, creates four distinct family communication patterns: protective, consensual, pluralistic, and laissez-faire (see Table 1).

These four family types fall onto the Family Communication Patterns based on their levels of conversation and conformity orientation. Conversation orientation is the amount and extent that family members feel free to communicate openly about their thoughts and feelings (Koerner \& Fitzpatrick, 2002a). Conformity orientation refers to whether a family stresses an environment of cohesive values, beliefs, and attitudes (Ledbetter \& Beck, 2014). Families that are high in conformity but low in conversation are protective families. Protective families do not believe that frequent interaction is necessary and do not routinely share emotions and experiences (Koerner \& Fitzpatrick, 2002a). Consensual families are high in conformity and high 
in conversation. Laissez-faire families have low conformity and low conversation, and pluralistic families have low conformity and high conversation.

\section{Table 1}

Family Communication Patterns

\begin{tabular}{|c|c|c|}
\hline & Conversation Orientation LOW & Conversation Orientation HIGH \\
\hline $\begin{array}{l}\text { Conformity } \\
\text { Orientation } \\
\text { HIGH }\end{array}$ & $\begin{array}{l}\text { Protective } \\
\text { - High conformity } \\
\text { - } \quad \text { Low conversation } \\
\text { - } \text { High interdependence } \\
\text { - } \quad \text { Sow Independence } \\
\quad \text { and conformity. } \\
\end{array}$ & $\begin{array}{l}\text { Consensual } \\
\text { - High conformity } \\
\text { - High conversation } \\
\text { - High interdependence } \\
\text { - Low independence } \\
\text { - Strive for a combination of } \\
\quad \text { conformity and openness. } \\
\end{array}$ \\
\hline $\begin{array}{l}\text { Conformity } \\
\text { Orientation } \\
\text { LOW }\end{array}$ & $\begin{array}{l}\text { Laissez-Faire } \\
\text { - } \quad \text { Low conformity } \\
\text { - } \quad \text { Low conversation } \\
\text { - } \quad \text { Low interdependence } \\
\text { No consistent norms, little } \\
\quad \text { parent/child communication. }\end{array}$ & $\begin{array}{l}\text { Pluralistic } \\
\text { - Low conformity } \\
\text { - High conversation } \\
\text { - Low interdependence } \\
\text { - High independence } \\
\text { - Ideas exchanged, but parents } \\
\\
\text { are not final authority. }\end{array}$ \\
\hline
\end{tabular}

Note. Four Family Communication Patterns developed by Koerner and Fitzpatrick (2002b).

There is a tension between hierarchy and the pressure to agree with the desire to divulge in open communication and new ideas (Koerner \& Fitzpatrick, 2002b). In the following pages, a more in-depth analysis of each family type will be explored. It is also important to remember that conversation and conformity orientation operate on a continuum (Koerner \& Schrodt, 2014). Family communication patterns are present in all families, but homeschooling settings provide a unique focus because parents are also teachers and children are also students. This additional time together as well as the additional responsibility of teacher and student add complexity to family communication patterns. Due to these unique circumstances, it is important to explore how the family pattern orientations relate to the family's instructional approach. 
In a family setting, "family communication environments are cognitive structures that influence communication behaviors" (Burns \& Pearson, 2011, p. 173). The family communication environments are influenced by everyday interactions and the common communication behaviors and topics that families participate in. In a homeschooling setting, a common communication behavior would be providing instruction and exploratory questioning. Depending on where the family falls on the conversation and conformity axis could influence how parents teach and how children learn.

In pluralistic families with high conversation orientation and low conformity, members feel like they can be open and honest with one another about their thoughts and emotions. These families could be associated with free and individualized thinking. Whereas a family with low conversation orientation and high conformity, a protective family, would feel like they could not share their thoughts and emotions and should not talk out against the established family norms. Families with low conversation orientation do not believe it is important to have frequent interaction and do not share emotions and experiences routinely (Koerner \& Fitzpatrick, 2002b). These families have been associated with less self-thought and more accepting of information based on the source (Kelly et al., 2002). The conversation and conformity orientation of all families is interesting but learning more about how those orientations impact homeschooling families is worth studying.

Understanding how communication styles play a role in families is vital to understanding how families interact with one another and interact with the world outside of the home. Families are supposed to be a safe place for growth, but not all families provide nurturing communication. For families that do not communicate often, parents and children are missing out on conversations about life, thoughts, dreams, plans, ideas, and daily updates. In low conversation 
settings, "parents in such families are less open about their emotions and less likely to encourage their children to express their own feelings" (Kelly et al., 2002, p. 207). If homeschooling families put parent in the role of teacher, and child in the role of student, then homeschool families should score higher on conversation orientation, but either high or low on conformity orientation, making them either consensual or pluralistic. Guan and $\operatorname{Li}(2017)$ found that "conversation orientation is a positive predictor of collaboration and compromise, and conformity orientation is a positive predictor of accommodation and avoidance" (p. 233). These factors can impact the level of relationship satisfaction reported.

\section{Protective}

Protective and consensual families are labeled as highly interdependent. This interdependence stems from the fear of disrupting the hierarchy and structures in place that make the family work, "a family is typically (but not always) characterized by a degree of interdependence among its members" (Ledbetter \& Beck, 2014, p. 246). The protective family communication pattern places emphasis on obedience and conformity. These families depend on parents for decision making and share core beliefs and values. Due to the centrality of power in a protective family, parents are usually viewed as being the absolute authority that children do not question. Protective parents stress directive behaviors and they typically engage in more punitive punishment measures; these practices do not foster individualization or psychological autonomy (Alt, 2016). Because of this imbalance of power and discussion, individuals in high conformity families, such as protective, are less likely to disclose to their parents, especially if they assume their parents will think they did something wrong (Bostwick \& Johnson, 2018). In relation to homeschooling, how protective families choose to provide instruction and delegate tasks could affect learning outcomes and student involvement. 
In a protective family, parents are the authority, so homeschooling in a protective family setting can be assumed to follow similar structure. In Thomas' (2016) qualitative study of homeschool families, one family stands out as high structure. The mother explained, "I am very structured" (p. 246) and that each day starts with the Pledge of Allegiance, bible study and then onto strict time slots for math, snack break, Christian education, grammar, and art. While this family was not classified into communication styles for Thomas' study, the stress placed on structure and order echoes protective characteristics.

\section{Consensual}

Consensual families are also classified as highly interdependent and they tend to strive for a combination of conformity and openness. This communication style is naturally a little tense, because the desire to be open often bumps heads with the desire for control. In consensual families, parents may spend a lot of time explaining their decisions and beliefs in hopes that children learn from and adopt them. Parents in a consensual family will listen to the child's thoughts and opinions, but ultimately make the final decision. Since children can discuss their ideas and opinions, but the parents ultimately make the final decision, children may feel like their thoughts do not actually matter. In consensual families, there is a sense of conformity among members and families that prioritize conformity tend to share less thoughts (Guan \& $\mathrm{Li}$, 2017). Ideas outside of the family norm, may ultimately get swept aside anyway, making members question bringing up their concerns in the first place.

In a homeschool scenario, it seems likely that the tension between parent and child would spill over into education. If parents have open dialogue with their children regarding their education, but ultimately make the final choice, it may be difficult for the child to feel invested in their learning. For example, if a student discusses a desire to explore science through hands-on 
Science, Technology, Engineering, and Math (STEM) experiments but the parent chooses an online learning module, the student may feel like their ideas about their education are not important. In high conformity families, parents are assumed to be the final authority, especially if the family in question values hierarchy. In these instances, children are more likely to resolve or avoid conflicts at their own expense to avoid tension or arguments (Guan \& Li, 2017). While protective and consensual are considered interdependent family communication patterns, the other two patterns, pluralistic and laissez-faire, are classified as independent.

\section{Pluralistic}

Pluralistic and laissez-faire families are low in conformity orientation and typically encourage members to share their opinions and engage in open dialogue before making decisions. The power in these family structures is more evenly distributed (Bostwick \& Johnson, 2018). Pluralistic families are characterized by low conformity and high conversation. Members exchange ideas in open dialogue and parents do not the need to be in control of all their child's decisions (Koerner \& Fitzpatrick, 2002b). Opinions are evaluated on merit and this family style can be classified as independent, meaning the family members can function freely on their own and do not depend on one source for sole authority or permission. Families that are low in conformity, such as pluralistic, value infidelity and encourage all family members to be involved in family decisions (Horstman et al., 2018). Previous research has connected this parenting style with well-adjusted students, high levels of involvement, reasoning, encouragement, and independence (Alt, 2016). Research on conversation-oriented families also suggests that children who grow up in these environments acquire the skills to manage relationships with conversation and confidence (Koesten \& Anderson, 2004). In addition to the four family communication patterns, there are also tools families use to maintain relationships. 
In a homeschool environment, a pluralistic family might leave some of the learning and structure to be determined by the parents, and other aspects to be determined by the children. Some of the families interviewed by Thomas (2016) explained that their household operates off multiple school schedules, letting the children decide when to wake up, start the day and when to end the day. One mother explained that her young child likes to start schoolwork early in the morning so that they can be done by afternoon. In the same house, her older child likes to sleep in, takes a ton of breaks during the day, and has no issues with completing work at night or on the weekends (Thomas, 2016). This freedom of choice, but with parental guidance, speaks to the highly independent nature and shared ownership of the pluralistic family style. This independent structure allows for parent and child choice and authority; whereas, the final family communication pattern has seemingly no authority structure.

\section{Laissez-Faire}

Laissez-faire families have low conformity and low conversation. There is a lack of consistent norms and little parent and child communication. These family members value personal space, independence, and relationship connections outside of the family (Horstman et al., 2018). These families believe that all members have the freedom to make their own decisions and do not place high value on family conversations (Koerner \& Fitzpatrick, 2006). These families are highly independent, meaning they frequently act on individual interest and are oftentimes not overly invested in one another's outcomes. This family can be considered freerange, where parents find it to be too much work to send their kids to school. They want studentdirected and student-led (Padilla, 2020). This parenting style is non-controlling and parents typically do not set formal rules or expectations for their children. Generally, there is very little 
use of punishment, chores, and minimal academic guidelines from parents (Alt, 2016). This communication style represents a weak effort at building bonds.

In relation to homeschool, a laissez-faire family would encourage self-discovery and selfguided instruction. An example of a homeschool day for this kind of family could look something like this:

The children do as they want, with some guidance from me. They read, experiment, game, draw, dance, nap-their choice. They attend workshops, support groups, Boy/Girl Scouts, community classes, etc. They often go to a friend's house to play or we have people at our house. (Thomas, 2016, p. 247)

While this learning style could work for some families, studies have shown that passive parenting is linked to reduced effort on learning and schoolwork, low levels of self-discipline, and poor adjustment to college life (Alt, 2016). The hands-off approach of a laissez-faire family and that approach to homeschooling could have a negative effect on student learning outcomes as well as personal growth and social outcomes. Laissez-faire families are less invested in one another than the other family communication types, and therefore may be less satisfied in the relationships.

\section{Perceptions of Homeschooling}

Various studies have shown that parent involvement is directly related to student academic achievement (Anthony \& Ogg, 2019; Barwagen, 2004; Lubienski et al., 2013). It should be noted, however, that measuring a homeschooled student's success is difficult because of the lack of consistency and methodology used from home to home. In order to fully understand academic achievement, it is imperative to highlight Collom's (2005) research and precautions for analyzing scores of homeschooled students: 
Not all homeschooled students take standardized achievement tests. Some parents shun these instruments. Indeed, they may have been one of the reasons that they opted out of the public schools. Therefore, those students who take standardized achievement tests may not represent homeschoolers as a whole. (p. 314)

Therefore, the lack of consistency regarding assessment makes it difficult to compare academic achievement among homeschoolers and comparatively to public school students.

One such study specifically examined ACT scores of high school students in public high school and homeschool settings and how their achievement related to their parent's involvement in their academics. Parent involvement was significantly related to student achievement in both public and homeschool settings and that, "no difference in achievement is found between homeschool students, who have natural parent involvement built into the model, and publicschool students who perceived high parent involvement" (Barwagen et al., 2004, p. 52). Student's perception of their parent's interest can be demonstrated through conversations and support regarding schoolwork, volunteering at school functions, and working with students on academic decisions.

Further, Barwagen et al.’s (2004) study suggests that, "even through the high school years, not only is this involvement important, it is imperative for high school students to believe that their parents have been involved throughout their school careers" (p. 51). Students with perceived high parental involvement in public school and homeschool performed about the same on their ACT, which debunks any myths about homeschool students outperforming their publicschool peers. The important factor is not school location, but parental investment. Homeschooling has the convenience of built-in involvement, so public-school parents may have 
to work a bit harder to demonstrate, or outright communicate to their children, how invested they are in their education.

Barwagen et al.'s (2004) argument is furthered in another study, that explains that high achieving homeschool students would most likely be just as successful if they attended public school. Their socioeconomic status and involved parents would follow them and help them be successful regardless the setting (Lubienski et al., 2013). The parental involvement is what makes the difference. Anthony and Ogg's (2019) longitudinal study found that school-based involvement and home to school communication significantly predict a student's reading achievement. They also found that it is important to develop strong parental involvement when students are in elementary school and maintain that parental involvement so students can benefit long term (Anthony \& Ogg, 2019). Interestingly, but perhaps not surprisingly, is that children and parents perceive involvement differently. It is important for parents to communicate with their child the ways in which they are involved in their education, because children do not always recognize the effort (Barwagen et al., 2004). Home and school relationships are crucial for students to be successful.

In some cases, the home and school, parent and child relationship can be too much, and parents can be too involved. It cannot be assumed that homeschool parents are overinvolved or overbearing, but there are certainly instances where it is the case. The term helicopter parent is used to describe parents that are hyper-involved in their children's lives (Kelly et al., 2017). Homeschool may seem to outsiders as a parent-controlled, helicopter style of education, which is why it is necessary to briefly address.

The term helicopter comes from the idea of parents circling around their children, making decisions for them, and not giving children the opportunity to mess up. It may come from a good 
place, but the overinvolvement can be developmentally detrimental. This type of environment can be overly interdependent in a non-healthy way (Givertz \& Segrin, 2014). In fact, studies on overparenting have demonstrated lower levels of family satisfaction (Stein et al., 2016).

Helicopter parents are high in guidance, but they can lack meaningful, emotion-driven conversation because the relationship is built on interdependence. This parenting style would most likely fall under the protective family communication pattern.

For some over-parented children, they may enjoy the hovering, or they may be unaware that it is a problem, because they have become accustomed to being directed (Givertz \& Segrin, 2014). It is important to note that helicopter children report lower levels of family satisfaction, less open communication, high conflict avoidance, and more problematic parent-child communication when the helicopter is their mother (Kelly et al., 2017). It is necessary understand helicopter parents at a surface level so that our research can dive into deeper connections and maintenance behaviors.

Understanding the role of parental involvement on grades and student success is crucial to understanding the relationship between homeschool parents and children. From building confidence to breaking it, there is a wide spectrum of parent involvement and child accountability. Once a family decides the level of involvement they will have, they will have in their child's homeschool education, they must determine the method of instruction. For some families, parents decide the educational content to cover and for others, children lead the way and parents act as guides. The literature on family communication patterns is crucial to this study, but also works in conjunction instructional communication, how the lessons are delivered. 


\section{Instructional Communication}

Homeschooling allows for parents to take charge of their child's education and lead the school day. According to Thomas (2016), researchers found that on average, most homeschooled students had a learning day of about four hours or less but participated in teachable moments outside of their school day. The flexibility of homeschooling is attractive to many families. It gives parents the authority to decide when school starts or stops, when breaks occur, how long lessons last, when and where lessons take place, and other variables. In Thomas' study, many of the participants cited individualized instruction as a driving factor in their decision to educate at home.

Educational essentialism is a traditional educational philosophy that is teacher-centered and focuses on high test scores and grades. Essentialist thinking is that "discipline and hierarchy are key elements of effective teaching” (Elgström \& Hellstenius, 2011, p. 721). This focus on discipline and core subjects has long been the image of public-school education. With essentialism, traditional subjects have more prominence and interdisciplinary and alternative subjects are not priorities (Larsson et al., 2010). The emphasis on hierarchy also means students have less of an opportunity to select subjects they are interested in (Fredholm, 2017). One of the main goals of educational essentialism is to transfer skills, facts, and social standards to the next generation of learners.

While some families turn to homeschool for flexibility, others may turn to it for increased structure and control. Traditional methods of teaching are teacher-centered, and students are passive learners, meaning they are expected to memorize content (Ahmed \& Ahmed, 2017). The practice of memorizing and regurgitating is called rote learning and it is a well-practiced and well-known technique. Most school systems operate off this teaching style even though the focus 
is more on memorization and test scores than comprehension and depth. Memorization learning can help develop deeper understanding and critical learning (Sinhaneti \& Kyaw, 2012). Student performance indicators are measurable data sets that can be used to determine if a student is understanding class content. Grades and grade point average are the most common tools used to determine student success.

When a student finds success with rote learning, it may inspire them to put more effort into their education and become a deeper learner. Parents have many options for choosing how to educate their child in homeschool but regardless of how they teach, their family communication patterns will influence how they get their message across.

Homeschool allows for students to take charge of their learning and for teachers to focus on the individual needs of the learning. In pedagogical studies, student-centered or learnercentered instruction are common terms that refer to students as the drivers of their own learning. As Brown-Wright (2011) explains it, student-centered learning, or better named, learner-centered methods require the student to control their learning rather than just absorbing information from lectures. Learner-centered does not mean teachers leave students to fend for themselves. It refers to developing students so that they are active in their learning, discovery, and can figure out what to do when they are faced with tasks that they are not familiar with (Goodyear \& Dudley, 2015). In this scenario, the teachers work as facilitator of learning and their job is to guide students and nudge them in the right direction when they need assistance, but not to get overinvolved so that the student can learn to be resilient and work through problems.

Teachers play an active role in the learning process. Their interaction with students during tasks helps break down barriers and help students interpret, understand, support, and develop learning concepts. One way in which teachers play an important role in the learning 
process is their ability to diagnose, respond to and evaluate student learning (Goodyear \& Dudley, 2015). In homeschooling, parents are afforded the opportunity to watch their child's growth in real time and respond to their learning needs in the moment. Teachers need to play an active role in the learning process so that students can extend their abilities and complete their learning tasks (Goodyear \& Dudley, 2015). Homeschool families have the time and flexibility so that learning can take place across time periods, whereas, traditional school settings do not have that luxury. Parents can guide lessons over hours, days, weeks, or even months until their student gains the mastery needed to move onto more complex issues. The benefit of time is the true advantage of a homeschooled student.

\section{The Power of the Pause}

Garcia and Conway (2019) discuss the importance of teachers providing a pause after asking questions so that students can think deeper about their responses versus feeling rushed to provide an answer quickly. This time to process allows students to dive deeper into their learning and really think about their answers. Additionally, if teachers wait a few seconds to respond to the student's answer, students have more time to elaborate and explain themselves. In a homeschool environment, teachers typically have more time flexibility which would give students a better opportunity to explore. In a pluralistic family, one that already values conversation and idea exchange, this time could be a huge benefit to student learning outcomes. Further, parents in this family type value discussion and would likely engage in the discovery with their child.

Slow thinkers, or individuals who take pause to examine a question before answering, are often problem finders, or individuals who like to take a problem and dive into discovery until they find the solution (Garcia \& Conway, 2019). They are problem solvers. Slow thinkers also 
tend to enjoy their own company, exhibit a sense of play, can remain highly focused for extended amounts of time, and can sustain thought (Garcia \& Conway, 2019). Slow thinkers would naturally thrive in most homeschool scenarios, given the ability of flexible learning. In a homeschool where families value exploration and a learner-centered method, students can really shine. When thinking of the power of the pause and slow thinkers, pluralistic families come to mind the most. It is possible that consensual families, those that are high in conversation and high in conformity could also benefit from this style, but their emphasis on conformity could be a barrier of student discovery and exploration if conversation is not highly valued.

Garcia and Conway's (2019) study on the value of student processing time discovered three important findings: quality over quantity, process over product, and collaboration versus competition. The first finding, quality over quantity is explained, "there is a need for more processing time to develop deeper understanding," requiring students to rush through work just to complete a task does not lead to quality learning, and collaboration is a stronger learning tool than competition (p. 12). The culture of many classrooms in the United States is one of hurriedness, stress, and competition. Students rush to learn tasks in 45-minute class periods, they stress out about grades, and they compete with other students for time and recognition. Garcia and Conway's research argues that this style of learning is not conducive to student success and long-term learning. Learner-centered instruction is gaining increased popularity in classrooms and showing promising signs of success.

\section{Gradeless Classrooms}

Homeschooling allows for learner-centered instruction, so long as the parents are willing to accommodate this instructional style. While homeschool families can issue grades to their students, and even create report cards and transcripts, they would be doing so for their own 
information since most states have low-to-no state mandated homeschooling requirements (HSDLA, 2020). In traditional public-school settings, grades, projects, and formal deadlines are generally part of the instructional structure. One traditional-school teacher learned about gradeless classrooms and the model of Summarizing, Explaining, Redirecting and Resubmitting and decided to apply it to his Career and Technical Education classroom (Hunt, 2019). The practice allows students to create their own projects, explain it to their team members, receive guidance and resubmit based on productive conversations. This style of classroom replicates a workplace environment wherein students, or workers, need to be able to think critically, adapt, and take charge of their work. The power to take control of one's work and learning can also create a renewed investment and desire to learn (Haber-Curan \& Tillapaugh, 2015). It seems that gradeless classrooms can be synonymous with learner-centered because it puts student passions at the forefront.

Hunt (2019) discovered that a learner-centered classroom is the best way for students to truly engage and find value in the work they are doing. Rather than looking at a rubric and trying to figure out the minimum they can do to pass the class, students are engaged in their projects because they have ownership over the work. In the case of Hunt's classroom, he found that giving the students a choice to decide their projects helped motivate them to do better work. Hunt also found that in his learner-centered classroom students seem to take more risks and collaborate more with their classmates (Hunt, 2019). Hunt's observations are also supported by theoretical research. According to Haber-Curan and Tillapaugh (2015), "as one's development becomes more complex, an individual recognizes the uncertainty of knowledge and actively engages in the process of ongoing inquiry" (p. 67). This is known as the reflective judgement model, or the theory that explains how individuals develop the ability to evaluate tough topics 
and articulate their beliefs on them (Love \& Guthrie, 1999). Students that are excited about their learning and discovery have the ability and consciousness to move onto more challenging problems when they are ready. For learner-centered classrooms to be successful, instructors must be willing to take more of a mentor role.

Homeschooling is characterized by parents providing instruction to students. A gradeless, learner-centered classroom seems to echo characteristics of the more independent family styles, laissez-faire and pluralistic. While laissez-faire families would likely be drawn to a gradeless, or learner-centered, classroom, their hands-off style would likely not lead to student success. Pluralistic families, or families that value high conversation and low conformity, would be the most open of the four family communication patterns to embrace a learner-centered instructional approach. Instructors play a huge role in creating learning environments and must be invested in the type of classroom they create. For the student-driven classrooms, instructors must stimulate action and encourage students to be critical, active learners (Haber-Curan \& Tillapaugh, 2015). Homeschooling parents that create a learner-centered classroom must do so by allowing for student discovery and learning, while offering guidance and knowledge when appropriate.

Family communication patterns and how they interact with instructional communication in the homeschool setting could impact how family members feel about one another. A parent's communicative patterns paired with their instructional communication style could cause the child to feel close to, or distant from their parent. Further, some family types could predetermine instructional approach because of their communication patterns. For instance, hands-on and student-led could be difficult for protective, or consensual families, as parents are the absolute authority. All these factors play a role in how happy a parent, or child, feels in the relationship 
with the other. Based on what has been previous family communication patterns studies the following research questions are presented.

$\mathrm{RQ}_{1}$ : Will conversation orientation will predict parents' homeschooling instructional approach?

$\mathrm{RQ}_{2}$ : Will conformity orientation will predict parents' homeschooling instructional approach?

\section{Relational Satisfaction}

Relationship satisfaction is how one feels about their relationship with another. For parents and children, relational satisfaction may be influenced by the family communication patterns. Additionally, in a homeschool environment, instructional communication could impact how a parent or child feels about and evaluates their relationship. Relational satisfaction can be observed through behaviors or acts, known as relationship maintenance, that show the level of satisfaction one feels in the relationship.

There are five dimensions of relationship maintenance: "positivity (being cheerful and supportive), openness (directly discussing the nature of the relationship), assurances (stressing one's love and commitment), social networks (involving friends and family), and shared tasks (doing one's share of responsibilities)" (Ledbetter \& Beck, 2014, p. 234). All five of these dimensions need to be present for successful relationships. These five dimensions have been studied widely in romantic relationships and scholars are now applying these dimensions via modified scales to family communication and family relational satisfaction (Ledbetter \& Beck, 2014; Shebib, 2020). With homeschool families, at least during the homeschool years, the relationship is forced by the parent. Parents have the right to determine to homeschool their children until they are 18, but children do not have much of a choice. From an outside 
perspective, one would assume that homeschool families are close-knit. They spend their school day together and their free time. While clubs, activities, and lessons do provide breaks in the schedule, much of their time is spent together. Knowing that homeschool families spend such a large amount of their time together, relationship satisfaction after homeschooling is over becomes an interesting component to explore.

A positive parenting style can influence how children view their parents and help cultivate a mentor-type relationship and respect versus authoritarian oversight. Schrodt's (2009) study explored expressiveness, structural traditionalism, and conflict avoidance to determine if they were related to family strength and satisfaction. Schrodt discovered expressiveness has a strong, positive association with family strength. This kind of parenting is dependent on openness on both sides to be successful, but when done correctly, could lead to stronger and lasting bonds. Findings from the research of Guan and Li (2017) indicate that family conflict communication can be stabilized with strong relational bonds.

Family-time schemas may noy be reliable predictors of communication behaviors in families that are more independent. Ledbetter and Beck's (2014) study broke down conversation and conformity interactions and discovered that at lower levels of conformity orientation, conversation orientation was less likely to predict relationship maintenance behaviors orientation. For families that are more interdependent, communication styles would have a greater impact on relationship maintenance. Children from a protective or consensual family may engage in dialogue with their parents for approval. For the interdependent families, relationship maintenance can become uncomfortable as children get older because everyday conversation topics could become a struggle as children begin to explore or participate in activities that do not align with their family values (Burns \& Pearson, 2011). As children get older, their need for 
control and dominance shifts, and parents should also shift to more age-appropriate conversations and behaviors (Bartholomew \& Horowitz, 1991). Further, it can be argued that the more pressure there is to avoid conflicts or disagreements, the more likely family members will report lower levels of satisfaction (Schrodt, 2009). Additionally, as children emerge into early adulthood, they begin to start seeing their parents differently.

Since the homeschool environment provides an environment where parents and children spend significantly more time together than children who leave the home to attend school, it seems possible that all that extra time together would impact relational satisfaction. Understanding what we know about instructional approaches, it also makes one wonder if the amount of input a child has on their educational explorations in homeschool impacts relational satisfaction. If a child has no say in their lessons, is it possible that they are not as satisfied with the relationship of their primary homeschool parent? It is also possible that it has no impact. It is interesting to explore how family communication patterns interact with relational satisfaction. Based on what has been previously studied on family communication patterns and relationships, the following research questions are presented.

$\mathrm{RQ}_{3}$ : Do perceptions of parent-child relational satisfaction differ between parents and children?

$\mathrm{RQ}_{4}$ : Will parents' homeschooling instructional approach predict parent-child relational satisfaction?

$\mathrm{RQ}_{5}$ : Will conversation orientation predict parent-child relational satisfaction?

$\mathrm{RQ}_{6}$ : Will conformity orientation predict parent-child relational satisfaction? 
Understanding perceptions of relational satisfaction as well as the way those perceptions interact with family communication patterns will provide insight into practices that homeschooling families may want to explore or avoid.

In emerging adulthood children require less parental control, so it is possible that the perception of parenting style could be affected simply by the age of the participants (Alt, 2016). In this study, participants must be over the age 18, therefore their responses are reflective of their homeschool days, versus in the moment. Previous research has found that families who communicate in ways that encourage open discussions of ideas and feelings, such environments may strengthen the family by equipping family members with the information-processing and behavioral skills needed to cope with internal and external forces (Schrodt, 2009). Alternatively, Stein et al. (2016) investigated why college-age students-maintained contact with parents via their cellphones. They found a significant correlation between those who reported highly that they felt obligation and how frequently they contacted home. Families with high conformity and high interdependence would most likely feel more obligation to call home. The communication environment makes a huge impact on how and what families share with one another and how satisfied they feel within the relationship. Relational satisfaction is the overall happiness and level of content and fulfillment one gets from a relationship, whereas closeness provides a magnified view of the relationship.

\section{Closeness}

Relational satisfaction is measured through maintenance behaviors and tells the story of the overall quality of the relationship. Closeness provides a measure of the quality of the affection within a relationship. Of all the relationships people experience in a lifetime, parentchild is one of the longest lasting. Although all relationships can come and go, "parent-child 
bonds, or their absence, tend to remain with us - if not physically, then often mentally and emotionally" (Golish, 2000, p. 79). Family closeness is different from family satisfaction because satisfaction deals with fulfillment while closeness deals with the day-to-day intergenerational relationships between family members. With all of this in mind, it is still important to explore how perceived family style interacts with communication and relationships. Family closeness is the child's feelings of parental warmth and involvement (Strage, 1998). How children interact, connect with and enjoy their parents' company are all components of closeness. The greater the closeness, the warmer the feelings, the better the relationship (Wang et al., 2018). The level of closeness families feel to one another can be examined through certain predictors and outcomes (Guan \& $\mathrm{Li}, 2017)$. For example, high conversation orientation is likely to be associated with collaboration and low conversation orientation is likely to be associated with conformity. Degrees of closeness can also change over time, with individuals getting closer, or more distant as time goes by.

Parent-child closeness is important because it is one of the most personal relationships one experiences in a lifetime. Parental closeness varies greatly even among siblings in one household. Understanding patterns in close relationships and determining the missing link in distant relationships is important to understanding parent-child closeness (Golish, 2000). Examining closeness in parent-child relationships over time can help us understand how bonds reconceptualize over time. While parent-child relationships can be filled with positive feelings like love and respect, they can also be plagued with negative feelings like hatred and anger (Cairns, 1977). Although parent-child relationships are complex and ever-changing, they are enduring. Arguments or negative experiences that end romantic relationships or friendships will probably be less likely to end a parent-child relationship since the relationship spans such a great 
time and seems to have more permanence. Parents also tend to appease their children and avoid conflict for the sake of relationship sustainability (Fingerman, 1995). Due to the investment that parents tend to feel in the relationship, they make it more difficult for children to break away. Not bringing up a touchy subject is just one-way parents work to keep their children close.

According to Golish (2000) stress or crisis events, age, and distance are three things that can affect closeness in adult child-parent relationships. "Children may feel close to their parents when they are young, a decrease in their level of closeness as they enter their teenage years, and then increase in their closeness as they reach adulthood" (p. 82). Closeness is important because it can be dependent on vulnerability in the relationship. Schrodt (2009) found that satisfaction was positively related to family expressiveness in addition to closeness.

The relationship between parents and children are influenced by memories, attributions, and experiences that they share with one another. These influences impact how the players in the relationship use communication and interpret conversations and behavior (Koerner \& Fitzpatrick, 2002a). The shared experience between parent and child are unique to those two individuals. Further, family communication is influenced by perceptions of family cohesiveness, conflict/resolution patterns, hierarchy, and rituals (Koerner \& Fitzpatrick, 2002b). Studying parent-child relationships is further complicated by the co-existing relationships with other parents and siblings. In homeschooling, one could argue that parents have more time to cultivate the relationship with their child because they have authority over how they teach the world to their child. The connection between parent and child is exclusive and distinguishable from all other relationships (Fletcher, 1993). If the parent-child connection is strong and based in positive memories and experiences, it could be hypothesized that as the child enters adulthood and has the freedom to decide who they communicate with, they would have a rich and mutually 
beneficial relationship with their parents. There is research to back this up too. Burns and Pearson (2011) found that what their study called expressive families, which matched the criteria for what otherwise would be referred to as pluralistic families, significantly predicted family satisfaction. Further, joking around, relationship talk, and recapping the day's events were most associated with the everyday talk that occurs in these families (Burns \& Pearson, 2011). The research demonstrates that families who talk to each other, and more importantly, enjoy each other, are happier. These happier people and their investment in one another, can also lead to more successful students.

$\mathrm{RQ}_{7}$ : Do perceptions of parent-child closeness differ between parents and children?

RQ8: Will parents' homeschooling instructional approach predict parent-child closeness?

$\mathrm{RQ}_{9}$ : Will conversation orientation will predict parent-child closeness?

$\mathrm{RQ}_{10}$ : Will conformity orientation will predict parent-child closeness?

\section{Conclusion}

Applying existing research on family communication patterns, instructional communication, relational satisfaction, and relational closeness provides a unique look into homeschooling. Insight into how families communicate and how instructional patterns interact with relational satisfaction and closeness can provide guidance on student learning and family bonding. Most communication research as well as family communication research fails to take into consideration the unique homeschool environment, wherein parents and children also fill the roles of teacher and student. Educating one's own children, and learning from one's own parent, will influence communication patterns as well as satisfaction and closeness.

The COVID-19 pandemic has made the traditional structure of the school day come into question. Families have been forced into homeschooling or remote learning and the relationship 
between parent and child when education is also part of the equation makes homeschool literature more relevant than ever before. Studying communication patterns and outcomes can help families examine how education takes place in their homes, and make changes where improvement is needed. If exploring communication theories in a new way can provide insight into best practices and patterns for families to utilize, it is content worth studying. 


\section{CHAPTER II: METHODS}

\section{Participants}

Quantitative survey data were collected from two groups of participants: homeschool students and parents. After Institutional Review Board approval, 135 responses were collected and of those, 43 were homeschool students and 92 were homeschool parents. Not all 135 participants completed the entire survey, as the demographic breakdowns will show. Participants for this study were sampled from a large public Midwestern university and were offered the opportunity to participate in the study via an online research board for students within the communication discipline. The survey was also sent out to a campus wide listserv for research. Additionally, the researcher posted the survey invitation on their personal Facebook page and emailed an invitation out to local homeschool cooperatives. Criterion sampling was used to ensure that participants were over the age of 18 and were either homeschooled for a period of at least one year during their academic career, or are a parent that provides or provided homeschool to their child(ren) for a period of at least one year. Some participants, at the discretion of their specific professor, received extra credit in their communication course for completing the survey. All respondents gave informed consent, were notified that they could stop the survey at any time and were assured their survey answers would remain anonymous.

The final homeschool student participant count was 38, and the sample was $81.6 \%$ White, 5.3\% Black or African American, 7.9\% bi-racial/mixed, and 5.3\% other. The age range of homeschool students was from 18-40 with a mean age of $25.08(S D=6.05)$. The biological sex distribution of the student's was primarily female at $84.2 \%$ and males accounted for the other $15.8 \%$. The time that the homeschool experience lasted ranged from 1-15 years, with a mean of 7.21 years. Students reported that homeschool was taught primarily by a female, $94.7 \%$, and 
5.3\% reported being taught by a male. Homeschool students reported that they experienced homeschool during all grade levels, with the following breakdown: 31 during elementary, 23 during middle, and 21 during high school. The time elapsed since the student was last homeschooled ranged from 1-22 years with a mean of $10.26(S D=5.83)$. Most participants reported that during homeschool they participated in a co-operative either all of the time, $2.6 \%$ or some of the time, $57.9 \%$ with the other $39.5 \%$ reporting that no co-operative participation.

The final homeschool parent participant count was 55, and the sample was 92.7\% White, 1.8\% Black or African American, 1.8\% Asian, 1.8\% bi-racial/mixed, and 1.8\% other. The age range of homeschool parents was from 18-61 with a mean age of $41.67(S D=7.97)$. The biological sex distribution of the parent's was again, primarily female, $94.6 \%$ and males accounted for the other 5.6\%. The time that parents reported that they taught homeschool ranged from 1-15 years with a mean similar to the student reports, at 7.22 years $(S D=4.88)$. Parents reported that the biological sex of the children they taught was $52.7 \%$ female and $47.3 \%$ male. Homeschool parents reported that they taught homeschool during all grade levels, with 50 reporting that they taught during elementary, 35 reporting during middle school, and 22 reporting that they taught homeschool for high school. The homeschool parents reported that the time elapsed since they last taught homeschool was a range of 0-2 years, with a mean of .93 ( $S D=$ .42), showing that the parent respondents are closer to the homeschool environment, as the student participants reported more time passed, mean of 10.26 years $(S D=5.83)$, since they were involved with homeschool. As with student responses, parents reported using co-operatives $27.3 \%$ all of the time, $54.5 \%$ some of the time, and $18.2 \%$ reported not using them at all. 


\section{Procedures}

Before participants could complete the online survey, they needed to confirm that they read the consent form. Once participants answered in the affirmative, that they had been homeschooled, or provided homeschooling for at least one year, they were prompted to a sorting question that asked them if they are either a homeschooled student, or a homeschooling parent. The answer to this question directed them to the appropriate set of questions. The surveys were almost identical, but child/parent were exchanged appropriately based on the survey taker. The data was not paired.

The online survey used multiple-item scales and a few stand-alone slider-scale questions, See Appendix for the full survey instrument. The measuring item scales helped collect data on instructional types, family communication patterns, relational satisfaction and closeness. A few sliding scales provided additional insight into the dynamics of their relationships. The measuring instruments consisted of both yes/no questions and Likert scales. The survey took approximately 25 minutes to complete and the participants' responses were anonymous because no unique identifiers, such as name, were asked.

\section{Measures}

\section{Homeschooling Instructional Approaches}

To determine if the homeschool setting practiced a learner-centered or instructor-centered instructional approach, a 20-item scale was developed. The Homeschooling Instructional Approach Scale pulls scenarios from both learner-centered and rote learning strategies to determine the instructional approach used in homeschool. The survey uses questions such as "During homeschool, I (my child) had a say in the coursework I (they) studied" with a 5-point 
Likert-scale from 1 (strongly disagree) and 5 (strongly agree). The answers helped determine if the homeschool environment was more traditional or learner-centered.

The homeschooling instructional approach scale measured student and parent perceptions of the homeschool approach that was used during their experience. The EFA procedure produced an acceptable one-factor solution. Both the KMO measure (.884) and Bartlett's test $\left[\chi^{2}=504.38\right.$ $(105), p<.001]$ were acceptable. One factor had eigenvalues greater than 1.00. The factor, which was labeled homeschooling instructional approach scale, consisted of 20 items related to student's perception the approach used during their homeschool experience. Five items were deleted from the factor for more reliable data. The one-factor solution, consisting of 15 items, explained $57.21 \%$ of the variance with an 8.58 eigenvalue. The final unidimensional solution produced an overall alpha coefficient reliability of .95 for the scale producing very good reliability. See Table 2 for factor loadings.

The homeschooling instructional approach scale also measured parent perceptions of the instructional approach. The parent EFA procedure produced an acceptable one-factor solution. Both the KMO measure (.799) and Bartlett's test $\left[\chi^{2}=146.03(10), p<.001\right]$ were acceptable. One factor had eigenvalues greater than 1.00. The factor, which was labeled homeschooling instructional approach scale, initially consisted of 20 items, but for parents, was paired down to five items. The one-factor solution, consisting of five items, explained $53.10 \%$ of the variance with an eigenvalue of 2.65. The final one-factor solution produced an overall alpha coefficient reliability of .84 for the scale, which is a very good reliability. See Table 3 for factor loadings. 


\section{Table 2}

Factor Loadings for Student Homeschooling Instructional Approach

Items

Factor Loadings

20. During homeschool, my parent provided regular feedback on my

$\underline{.848}$ work.

9. My parent made sure I fully understood before moving onto a new

.827 lesson.

11. My parent helped me with difficult assignments and concepts.

.822

8. My parent played an active role in my learning process.

$\underline{.809}$

18. My parent and I engaged in frequent communication regarding my

$\underline{.796}$ schoolwork.

4. The homeschool environment was flexible enough to meet my needs.

$\underline{.771}$

14. During lessons, my parent was engaged in my learning.

.769

19. During homeschool, my parent took pride in my school work and

$\underline{.750}$ projects.

17. In homeschool, my parent acted as a guide during lessons when I required it.

13. My parent was very involved in my school work.

.$\underline{722}$

5. I felt concerns I had regarding my education were considered and

$\underline{.713}$

discussed.

2. I received a lot of "hands-on" and discovery learning.

$\underline{.704}$

16. In our homeschool, my parent and I both understood the expectations

.699

for school work.

15. During homeschool, my parent and I discussed my interests and

$\underline{.695}$ planned lessons accordingly.

6. During lessons, we discussed material and applied it to real life/world experiences.

$$
\text { Eigenvalue } \quad 8.58
$$

$\%$ of Variance $\quad 57.2 \%$

Cronbach's Alpha

Note. Factor loadings that met the 60/40 loading criteria are underlined. 


\section{Table 3}

Factor Loadings for Parent Homeschooling Instructional Approach Items Factor Loadings

20. During homeschool, I provided regular feedback on my child's work. .940

17. In homeschool, I acted as a guide during lessons when my child required it.

18. My child and I engaged in frequent communication regarding their schoolwork.

19. During homeschool, I took pride in my child's school work and .651 projects.

16. In our homeschool, my child and I both understood the expectations for school work.

Eigenvalue
$\%$ of Variance
Cronbach's Alpha

Note. Factor loadings that met the 60/40 loading criteria are underlined.

\section{Communication and Conformity Orientation}

To measure family communication styles, the Revised Family Communication Pattern Instrument (RFCP; Fitzpatrick \& Ritchie, 1990) was used to measure communication orientation. While the RFCP does offer a scale for conformity orientation, current research has demonstrated the conformity scale on RFCP to be a bit outdated, oversimplified and harsh (Horstman et al., 2018). The Expanded Conformity Orientation Scale (ECOS) is the revised conformity scale, ECOS expands on the RFCP and has been utilized and verified by current scholars in the field (Horstman et al., 2018; Shebib, 2020). Conversation orientation was measured with 15 items, using a 7-point Likert-scale from 1 (strongly disagree) to 7 (strongly 
agree) asking questions like, "My parents often ask my opinion when the family is talking about something." Conformity orientation was measured with the new scale, consisting of 24 items, using a 7-point Likert scale from 1 (strongly disagree) to 7 (strongly agree), with items such as "In our home, my parents have the last word." The wording of the scales was adjusted based on if the individual is reporting as a student or parent. According to Guan and Zi (2017), "the RFCP has moderate to high reliabilities with an average of Cronbach's $\alpha=.85$ for each orientation" (p. 223). The ECOS has a reliability of .89 (Horstman et al., 2018).

Communication and conformity orientation were measured using the RFCP scale and ECOS scale, respectively. These EFAs were reliable and consistent with the reputation of reliability these scales are known for (Shebib, 2020). For RFCP, the student group reliability was run with all 15 items, resulting in Cronbach's $\alpha=.94$, which is excellent. For student ECOS, all 24 items produced a reliability of .92 , which is excellent. The parent data also provided excellent reliability, producing a Cronbach's $\alpha=.91$ for the 15-item RFCP scale, and .91 for the 24-item ECOS scale.

\section{Parent-Child Relational Satisfaction}

To measure relationship satisfaction between homeschool children and parents a modified version of Hendrick's (1988) Relational Assessment Scale was used. The original scale has a mean interim correlation of .49 and an alpha of .86 (Hendrick, 1988). After revisions, the modified relational satisfaction assessment scale included five items, all with 7-point Likert-type response scales. Participants answered questions like, "How well does this parent/child meet your needs?" The answers for the Likert-type scales vary based on the question, for example, 1 (not at all or no problems) and 7 (very well or lots of problems). 
The modified relational satisfaction assessment scale consisted of five questions, but through EFA, one item, "How many problems are there in your relationship with this parent?" proved to be problematic, so it was eliminated, resulting in a four-factor scale for students. The student EFA procedure produced an acceptable one-factor solution. The KMO measure (.779) and Bartlett's test $\left[\chi^{2}=.97 .383(6), p<.001\right]$ were acceptable. The factor, which was labeled Child Relational Satisfaction, referred to the student's relational satisfaction with the parent that provided the majority of their homeschool instruction. The one-factor solution, consisting of four items, explained $68.98 \%$ of the variance with an eigenvalue of 2.76 . The final one-factor solution produced an overall alpha coefficient of very good, at .89. See Table 4 for student factor loadings.

\section{Table 4}

Factor Loadings for Student Relational Satisfaction

Items Factor Loadings

2. In general, how satisfied are you with your relationship with this parent?

3. How good is your relationship with this parent compared to most?

$\underline{.959}$

.878

1. How well does this parent meet your needs?

$\underline{.739}$

4. How much do you love this parent?

$\underline{.723}$

Eigenvalue $\quad 2.76$

$\%$ of Variance $\quad 68.98 \%$

Cronbach's Alpha

.89

Note. Factor loadings that met the 60/40 loading criteria are underlined. 
For parents, the same modified relational satisfaction assessment scale was used, and through factor analysis, the five-question survey was paired down to a three-question survey. For parents, the same question that plagued the student data regarding the number of problems in the relationship was also an issue. However, the problem question was eliminated after the bigger problem, which was the question, "How much do you love this child?" The parent EFA procedure produced an acceptable one-factor solution. The KMO measure (.673) and Bartlett's test $\left[\chi^{2}=60.259(3), p<.001\right]$ were acceptable. The factor, which was labeled Parent Relational Satisfaction, referred to the parent's relational satisfaction with the student they homeschooled and were focusing on for the entirety of the survey The one-factor solution, consisting of three items, explained $59.26 \%$ of the variance with an eigenvalue of 1.77 . The final single-factor solution produced an overall alpha coefficient of .76, which is respectable. See Table 5 for parent factor loadings.

\section{Table 5}

Factor Loadings for Parent Relational Satisfaction

Items

Factor Loadings

3. How good is your relationship with this child compared to most? .862

2. In general, how satisfied are you with your relationship with this child?

$\underline{.823}$

1. How well does this child meet your needs? .598

$\begin{array}{rr}\text { Eigenvalue } & 1.77 \\ \text { \% of Variance } & 59.26 \% \\ \text { Cronbach's Alpha } & .76\end{array}$

Note. Factor loadings that met the 60/40 loading criteria are underlined. 


\section{Parent-Child Closeness}

To measure parent-child closeness, a revised version of the Closeness to Parents Scale (Buchanan et al., 1991) was used. This scale is referred to as the modified relational closeness scale throughout the remainder of this thesis. All participants answered questions like, "How well does your parent/child know what you are really like? and, "How openly do you talk with your parent/child?" Cronbach's alpha is .89 for mothers and .90 for fathers (Buchanan et al., 1991). The scale consists of 10 questions, all with 5-point Likert-scales from 1 (not at all) to 5 (very likely).

For homeschool students and parents, relational closeness was measured with the 10-item modified relational closeness scale. For both students and parents, the final scales were slightly shorter, 8 items for students, and three items for parents. For students, the EFA procedure produced an acceptable one-factor solution. The KMO measure (.821) and Bartlett's test $\left[\chi^{2}=\right.$ 253.166 (28), $p<.001]$ were acceptable. The factor, which was labeled Child Relational Closeness, consisted of eight items related to students' feelings of closeness to the parent that primarily provided their homeschooling. The one-factor solution, consisting of eight items, explained $64.52 \%$ of the variance with a 5.16 eigenvalue. The final unidimensional solution produced an overall alpha coefficient reliability of .92 for the scale producing very good reliability. See Table 6 for factor loadings.

For parents, the EFA procedure produced an acceptable one-factor solution after trimming the scale down to three items. The KMO measure (.753) and Bartlett's test $\left[\chi^{2}=108.91\right.$ (3), $p<.001]$ were acceptable. The factor, which was labeled Parent Relational Closeness, consisted of three items related to parents' feelings of closeness to the child they provided homeschooling to. The one-factor solution, consisting of three items, explained $75.60 \%$ of the 
variance with an eigenvalue of 2.26. The final unidimensional solution produced on overall alpha coefficient reliability of .90 , which is very good. See Table 7 for factor loadings.

\section{Table 6}

Factor Loadings for Student Relational Closeness

Items

Factor Loadings

4. Is your parent interested in talking when you want to talk? $\underline{.896}$

7. Do you feel close to this parent? .880

6. Does your parent know what you are really like? $\underline{.858}$

10. Is this parent interested in the things you do?

9. If you needed money, do you feel comfortable asking this parent?

8. Would your parent help you if you had a problem? .761

1. Do you talk openly with your parent?

5. Does your parent frequently express affection for you?

.684

$$
\text { Eigenvalue } \quad 5.16
$$

$\%$ of Variance

$64.52 \%$

Cronbach's Alpha

.92

Note. Factor loadings that met the 60/40 loading criteria are underlined.

\section{Perceptions of Homeschooling}

Scaled questions using a number slider from 0 to 100 were used for additional information that was not answered with existing scales. The purpose of these scaled questions was to supplement the existing scales within the survey to get a direct read from the participant on these topics. For students, the results consisted of 39 valid responses and for parents, 58 valid 
responses. The first scaled question, "How would you rate homeschool prepared you/your child for the future?" had a student mean of $69.08(S D=31.91)$. For parents, there was a mean of $89.40(S D=12.22)$. The second scaled question, "Do you think homeschool improved your relationship with your parent/child?" yielded 39 valid student responses with a mean of 78.00 $(S D=26.02)$ and 58 valid parent responses with a mean of $93.29(S D=9.71)$

\section{Table 7}

Factor Loadings for Parent Relational Closeness

\begin{tabular}{ll}
\hline Items & Factor Loadings
\end{tabular}

7. Do you feel close to this child? $\quad \underline{.889}$

8. Would your child help you if you had a problem?

5. Does your child frequently express affection for you? $\quad \underline{.850}$

$\begin{array}{rc}\text { Eigenvalue } & 2.26 \\ \% \text { of Variance } & 75.60 \% \\ \text { Cronbach's Alpha } & .90\end{array}$

Note. Factor loadings that met the 60/40 loading criteria are underlined.

\section{Data Analysis}

To examine the relationships between instructional communication, family communication, parent-child relational satisfaction and parent-child closeness the data was run using simple regressions. These statistical tests were run with SPSS to investigate the research questions presented. Research questions one, two, and three all involved continuous independent and dependent variables. All three questions were explored with a simple regression, RQ1 examined whether conversation orientation, pulled from the RFCP, would predict parents' 
homeschooling instructional approach. The independent variable, instructional approach, was continuous and data were drawn from the homeschooling instructional approach scale. The dependent variable, conversation orientation, was also continuous and answers to the question regarding perceived preparation for the future. RQ2 explored how conformity orientation, predicted parent's homeschooling instructional approach. This question used conformity orientation as the continuous independent variable from the ECOS and the instructional approach as the continuous dependent variable.

RQ4 is parent's instructional approach would predict parent-child relational satisfaction RQ4 had a continuous independent variable, parental satisfaction, and a continuous dependent variable, instructional approach. The continuous independent variable was pulled from the results of the modified relational satisfaction assessment scale and the continuous dependent variable was pulled from the homeschooling instructional approach scale.

As with the first four research questions, the rest were also analyzed with simple regressions. RQ5 asked if conversation orientation would predict parent-child relational satisfaction. Conversation orientation, the continuous independent variable, was pulled from the RFCP, and parent-child relational satisfaction was pulled from the modified relational satisfaction assessment scale. RQ6 asked if conformity orientation would predict parent-child relational satisfaction. The independent variable was the continuous conformity orientation scale from the ECOS and the continuous dependent variable was pulled from the modified relational satisfaction assessment scale. RQ8 questioned if parents' homeschooling approach would predict parent-child closeness. For this question, the independent variable, instructional approach, was pulled from the homeschooling instructional approach scale, and closeness, the dependent variable, was pulled from the results of the modified relational closeness scale. RQ9 explored if 
parents' conversation orientation predicts parent-child closeness. Parental closeness was the continuous dependent variable and conversation orientation was the continuous independent variable. The data for RQ9 was run using results of the modified relational closeness scale and the homeschooling instructional approach scale. RQ10 asked if conformity orientation would predict parent-child closeness. Using the conformity orientation scale from the ECOS as the continuous independent variable and the modified relational closeness scale as the continuous dependent variable. 


\section{CHAPTER III: RESULTS}

\section{Regression Models for Instructional Approach}

For RQ1, a simple regression determined whether the parent's conversation orientation could predict their instructional approach, either learner-centered, or instructor-centered. Missing cases were excluded pairwise. For student responses, the results of the regression indicated that $50 \%$ of the variance in the student's perceived parental conversation orientation could predict the perceived parental instructional approach to homeschooling. $R_{\text {adj }}^{2}=.495, F(1,40)=41.18, p<$ .001. More specifically, the results of the regression procedure indicated that student's perceived parental conversation orientation positively predicted a significant amount of variance in the perceived parental instructional approach. Analysis of regression coefficients indicated that the conversation orientation, $\beta=.71, t=6.41, p<.001,95 \% \mathrm{CI}[.45, .88]$ was a significant predictor. When confidence intervals (CI) do not have a zero between the lower and upper-bound CIs it means we have confidence in the probability of the results. The student's perceived parental conversation orientation for parents did not produce Tolerance or Variance Inflation Factor (VIF) statistics indicating collinearity.

Results of the regression analysis for RQ1 indicated that $34 \%$ of the variance in the parent's conversation orientation could predict the parent's instructional approach to homeschooling, $R_{a d j}^{2}=.330, F(1,64)=33.03, p<.001$. More specifically, the results of the regression procedure indicated that parent's conversation orientation positively predicted a significant amount of variance in the parent's instructional approach. Analysis of regression coefficients indicated that the conversation orientation, $\beta=.58, t=5.74, p<.001,95 \% \mathrm{CI}[.35$, .72] was a significant predictor. The conversation orientation for parents did not produce Tolerance or VIF statistics indicating collinearity. See Tables 8 and 9 for beta weights. 


\section{Table 8}

Beta Weights for Student RFCP Predicting Instructional Approach

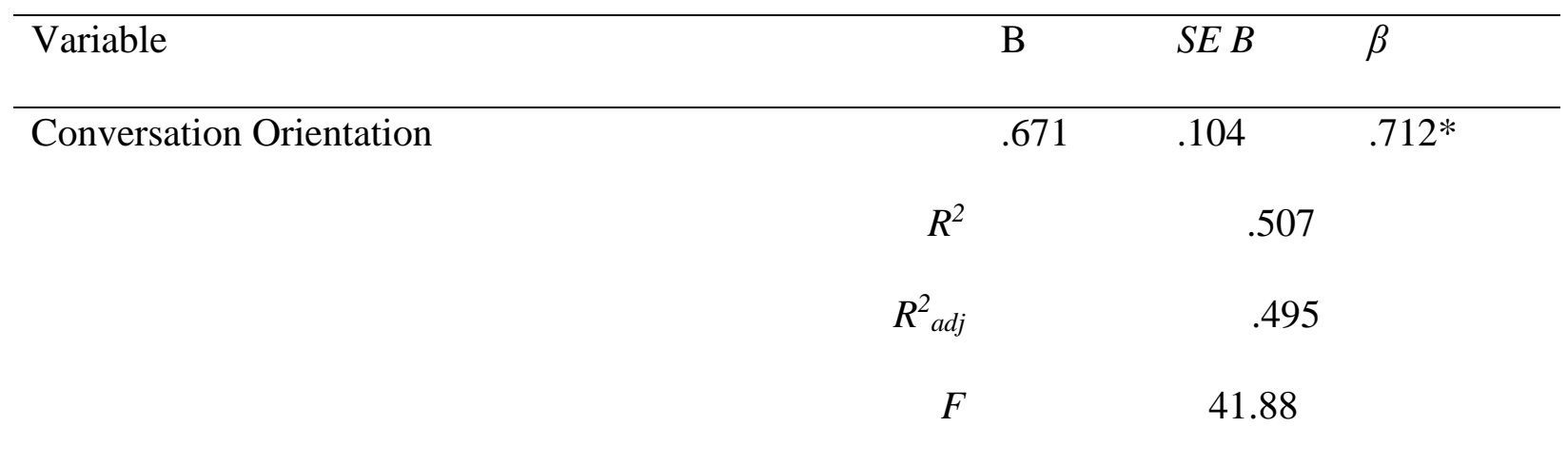

Note. An $*$ indicates significance at $p<.05(n=42)$.

\section{Table 9}

Beta Weights for Parent RFCP Predicting Instructional Approach

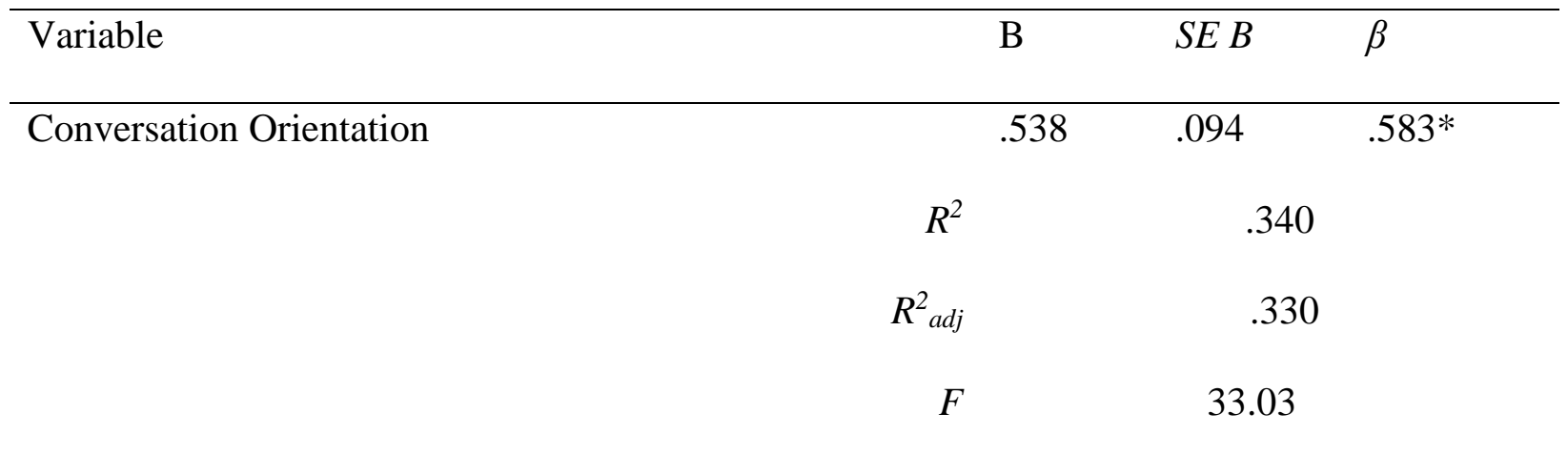

Note. An $*$ indicates significance at $p<.05(n=66)$.

With RQ2, another simple regression was performed to see if the parent's conformity orientation could predict their instructional approach. Missing cases were excluded pairwise. For student responses, the results of the regression analysis indicated that $12.8 \%$ of the variance in the student's perceived parental conformity orientation could predict the student's perceived parental instructional approach to homeschooling. $R^{2}{ }_{a d j}=.105, F(1,38)=5.59, p=.02$. More specifically, the results of the regression procedure indicated that student's perceived parental 
conformity orientation positively predicted a significant amount of variance in the perceived parental instructional approach. Analysis of regression coefficients indicated that the conformity orientation, $\beta=-.358, t=-2.36, p=.02,95 \% \mathrm{CI}[-.58,-.04]$ was a significant negative predictor of student's perceived parental instructional approach. The student's perceived parental conformity orientation for parents did not produce Tolerance or VIF statistics indicating collinearity. See Table 10 for beta weights.

\section{Table 10}

Beta Weights for Student ECOS Predicting Instructional Approach

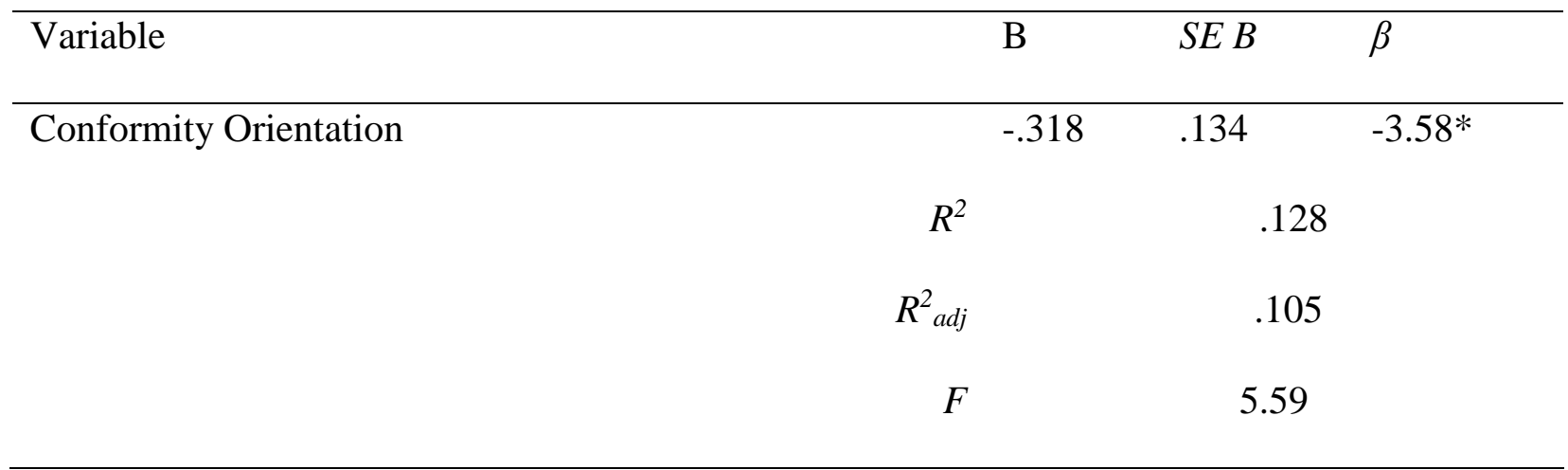

Note. An $*$ indicates significance at $p<.05(n=40)$.

For parents, results of the regression analysis indicated that $5.9 \%$ of the variance in the parent's conformity orientation could predict the parent's instructional approach to homeschooling, $R_{a d j}^{2}=.043, F(1,62)=3.85, p=.05$. The results of the regression indicated that the parent's conformity orientation did not predict a significant amount of variance in the parent's instructional approach. Analysis of regression coefficients indicated that the conformity orientation, $\beta=.242, t=1.96, p=.54,95 \%$ CI $[-.003, .30]$ was not a significant predictor. The conformity orientation for parents did not produce Tolerance or VIF statistics indicating collinearity. See Table 11 for beta weights. 


\section{Table 11}

Beta Weights for Parent ECOS Predicting Instructional Approach

\begin{tabular}{|c|c|c|c|}
\hline Variable & B & $S E B$ & $\beta$ \\
\hline \multirow[t]{4}{*}{ Conformity Orientation } & .151 & .077 & $.242 *$ \\
\hline & $R^{2}$ & .059 & \\
\hline & $R_{a d j}^{2}$ & .043 & \\
\hline & $F$ & 3.85 & \\
\hline
\end{tabular}

Note. An * indicates significance at $p<.05(n=64)$.

RQ3 asked if perceptions of parent-child relational satisfaction differed between parents and children. This was supposed to be an independent-samples $t$-test, but the results did not produce the data necessary to conduct a $t$-test. For children, there were 39 valid responses with a mean of $2.67(S D=.51)$ and for parents, there were 60 valid responses with a mean of $2.78(S D=$ .37). See Table 12 for descriptive statistics.

\section{Table 12}

Descriptive Statistics for Relational Satisfaction

\begin{tabular}{lcc}
\hline & Student Relational Satisfaction (4 Items) & Parent Relational Satisfaction (3 items) \\
\hline Valid $N$ & 39 & 60 \\
Missing & 96 & 75 \\
$M$ & 2.67 & 2.78 \\
$S D$ & .51 & .37 \\
\hline
\end{tabular}




\section{Regression Models for Relational Satisfaction}

The goal of RQ4 was to determine if a parent's homeschooling instructional approach would predict parent-child relational satisfaction. Missing cases were excluded pairwise. As shown in Table 13, results of the student regression indicated that for students, $36.5 \%$ of the variance explained in Student Relational Satisfaction was positively predicted by the Instructional Approach, $R_{a d j}^{2}=.347, F(1,37)=21.22, p<.001$. The significant results of the regression procedure indicate that student's perception of the instructional approach used in their homeschooling positively predicted a significant amount of variance in relational satisfaction. Analysis of regression coefficients indicated that the instructional approach, $\beta=.604, t=4.60, p$ $<.001,95 \%$ CI $[.20, .53]$ was a significant predictor. The conformity orientation for parents did not produce Tolerance or VIF statistics indicating collinearity.

\section{Table 13}

Beta Weights for Instructional Approach Predicting Student Relational Satisfaction

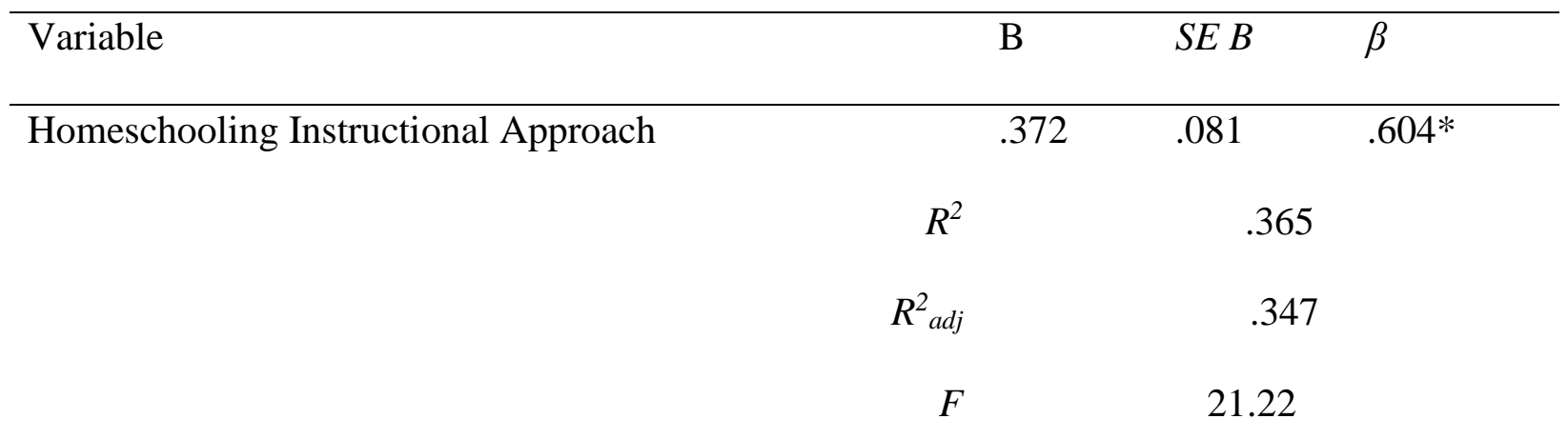

Note. An $*$ indicates significance at $p<.05(n=39)$.

For parents, results of the regression indicated that $9.3 \%$ of the variance explained the Parent Relational Satisfaction was positively predicted by the Instructional Approach, $R^{2}{ }_{a d j}=$ $.078, F(1,58)=5.97, p=.01$, shown in Table 14. Missing cases were excluded pairwise. The 
significant results of the regression procedure indicate that parent's perception of their instructional approach used in homeschooling positively predicted a significant amount of variance in relational satisfaction. Analysis of regression coefficients indicated that instructional approach, $\beta=.306, t=2.44, p=.01,95 \%$ CI [.04, .43] was significant predictor for parents. The parent instructional approach and parent relational satisfaction did not produce Tolerance or VIF statistics indicating collinearity.

\section{Table 14}

Beta Weights for Instructional Approach Predicting Parent Relational Satisfaction

\begin{tabular}{|c|c|c|c|}
\hline Variable & B & $S E B$ & $\beta$ \\
\hline \multirow[t]{4}{*}{ Homeschooling Instructional Approach } & .239 & .098 & $.306^{*}$ \\
\hline & $R^{2}$ & .093 & \\
\hline & $R^{2}{ }_{a d j}$ & .078 & \\
\hline & $F$ & 5.97 & \\
\hline
\end{tabular}

Note. An $*$ indicates significance at $p<.05(n=60)$.

RQ5 asked if conversation orientation would predict parent-child relational satisfaction. Missing cases were excluded pairwise. For students, results of the regression analysis indicated that $43.5 \%$ of the variance in parent-child relational satisfaction was positively predicted by conversation orientation, $R_{a d j}^{2}=.420, F(1,37)=28.50, p<.001$. More specifically, the significant results of the regression procedure indicated that student's family conversation orientation positively predicted a significant amount of variance in parent-child relational satisfaction. Analysis of regression coefficients indicated that conversation orientation, $\beta=.660$, $t=5.33, p<.001,95 \%$ CI $[.23, .52]$ was significant predictor for students. The student's family 
conversation orientation and student relational satisfaction did not produce Tolerance or VIF statistics indicating collinearity. See Table 15 for beta weights.

\section{Table 15}

Beta Weights for Student RFCP Predicting Relational Satisfaction

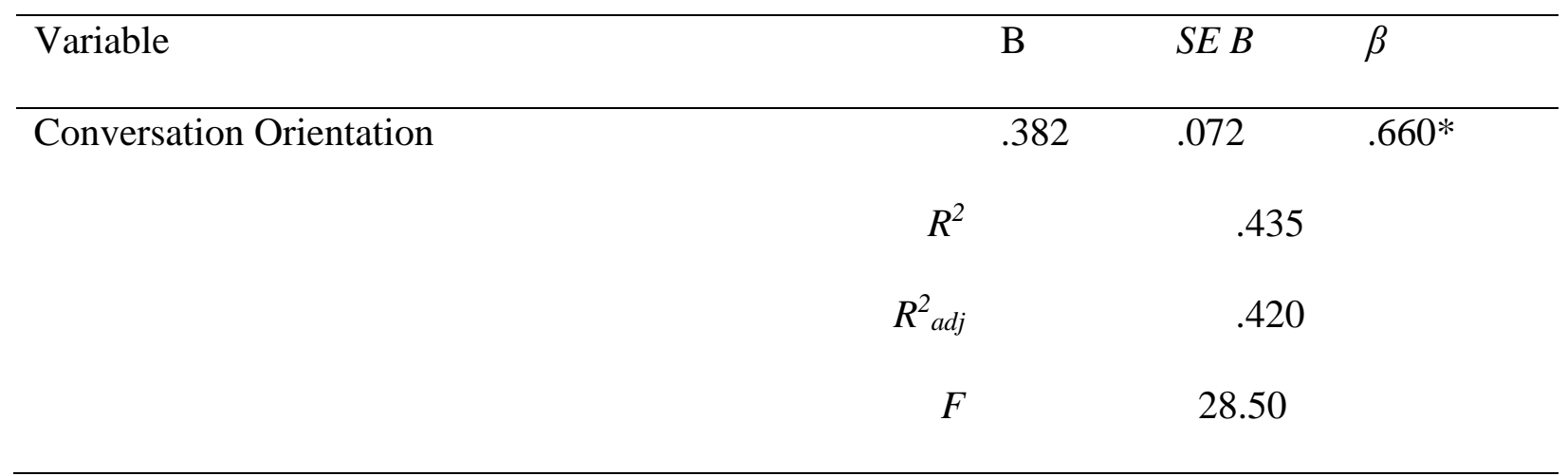

Note. An * indicates significance at $p<.05(n=39)$.

RQ5 also asked if conversation orientation would predict parent-child relational satisfaction for parents. Missing cases were excluded pairwise. For parents, results of the regression analysis indicated that $3.9 \%$ of the variance in parent-child relational satisfaction was positively predicted by conversation orientation, $R^{2}{ }_{a d j}=.023, F(1,58)=2.37, p=.12$, as shown in Table 16. More specifically, the non-significant results of the regression procedure indicated that parent's family conversation orientation positively predicted a significant amount of variance in parent-child relational satisfaction. Analysis of regression coefficients indicated that conversation orientation, $\beta=.198, t=1.54 p=.12,95 \%$ CI $[-.04, .32]$ was not a significant predictor for parents. The parent's family conversation orientation and parent relational satisfaction did not produce Tolerance or VIF statistics indicating collinearity. 


\section{Table 16}

Beta Weights for Parent RFCP Predicting Relational Satisfaction

\begin{tabular}{|c|c|c|c|}
\hline Variable & B & $S E B$ & $\beta$ \\
\hline \multirow[t]{4}{*}{ Conversation Orientation } & .143 & .093 & $.198 *$ \\
\hline & $R^{2}$ & .039 & \\
\hline & $R_{a d j}^{2}$ & .023 & \\
\hline & $F$ & 2.37 & \\
\hline
\end{tabular}

Note. An $*$ indicates significance at $p<.05(n=60)$.

RQ6 asked if conformity orientation would predict relational satisfaction. Missing cases were excluded pairwise. As shown in Table 17, or students, results of the regression analysis indicated that $14.5 \%$ of the variance in parent-child relational satisfaction was negatively predicted by conformity orientation, $R_{a d j}^{2}=.122, F(1,37)=6.25, p=.01$. More specifically, the results of the regression indicated that student's family conformity orientation negatively predicted a significant amount of variance in parent-child relational satisfaction. In other words, the more conformity orientation, the less relational satisfaction. Analysis of regression coefficients indicated that conformity orientation, $\beta=-.380, t=8.69, p=.01,95 \% \mathrm{CI}[-.37,-.03]$ was a significant predictor for students. The student's family conformity orientation and student relational satisfaction did not produce Tolerance or VIF statistics indicating collinearity.

RQ6 also asked if conformity orientation would predict parent-child relational satisfaction for parents. Missing cases were excluded pairwise. For parents, results of the regression analysis indicated that $.1 \%$ of the variance in parent-child relational satisfaction was not predicted by conformity orientation, $R_{a d j}^{2}=-.017, F(1,58)=.03, p=.84$. This is demonstrated in Table 18. More specifically, the non-significant results of the regression 
procedure indicated that parents' family conformity orientation did not predict a significant amount of variance in parent-child relational satisfaction. Analysis of regression coefficients indicated that conformity orientation, $\beta=-.026, t=.19, p=.84,95 \%$ CI $[-.14, .11]$ was not a significant predictor for parents. The parent's family conformity orientation and parent's relational satisfaction did not produce Tolerance or VIF statistics indicating collinearity.

\section{Table 17}

Beta Weights for Student ECOS Predicting Relational Satisfaction

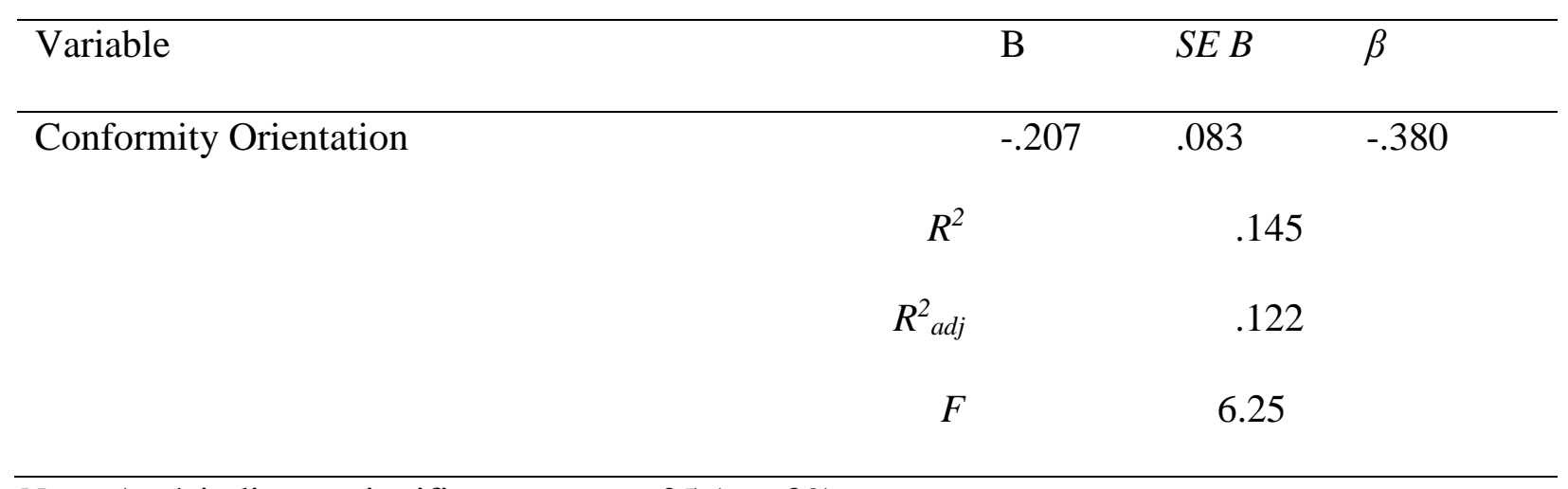

Note. An * indicates significance at $p<.05(n=39)$.

\section{Table 18}

Beta Weights for Parent ECOS Predicting Relational Satisfaction

\begin{tabular}{|c|c|c|c|}
\hline Variable & B & $S E B$ & $\beta$ \\
\hline \multirow[t]{4}{*}{ Conformity Orientation } & -.012 & .064 & -.026 \\
\hline & $R^{2}$ & .001 & \\
\hline & $R_{a d j}^{2}$ & -.017 & \\
\hline & $F$ & .038 & \\
\hline
\end{tabular}

Note. An * indicates significance at $p<.05(n=60)$. 
RQ7 was similar, asking if perceptions of parent-child closeness differed between parents and children. For children, there were 40 valid answers with a mean of $4.21(S D=.90)$ and for parents, there were 40 valid responses with a mean of $4.46(S D=.74)$. Descriptive statistics are provided in Table 19.

\section{Table 19}

Descriptive Statistics for Relational Closeness

\begin{tabular}{lcc}
\hline & Student Relational Closeness (8 items) & Parent Relational Closeness (3 items) \\
\hline Valid $N$ & 40 & 60 \\
Missing & 95 & 75 \\
$M$ & 4.21 & 4.46 \\
$S D$ & .90 & .74 \\
\hline
\end{tabular}

\section{Regression Models for Parent-Child Closeness}

Another research question, RQ8, asked, "Will parents' homeschooling instructional approach predict parent-child closeness?” Missing cases were excluded pairwise. As shown in Table 20, results of the regression indicate that for students, $42.5 \%$ of the variance in parentchild closeness was positively predicted by the homeschooling instructional approach, $\mathbf{R}_{a d j}=$ $.410, F(1,38)=28.09, p<.001$. The significant results of the regression procedure indicate that student's reported instructional approach positively predicted a significant amount of variance in parent-child closeness, $\beta=.652, t=5.30, p<.001,95 \%$ CI $[.43, .97]$ was significant predictor for students, the parent-child closeness and instructional approach did not produce Tolerance or VIF statistics indicating collinearity. 


\section{Table 20}

Beta Weights for Instructional Approach Predicting Student Relational Closeness

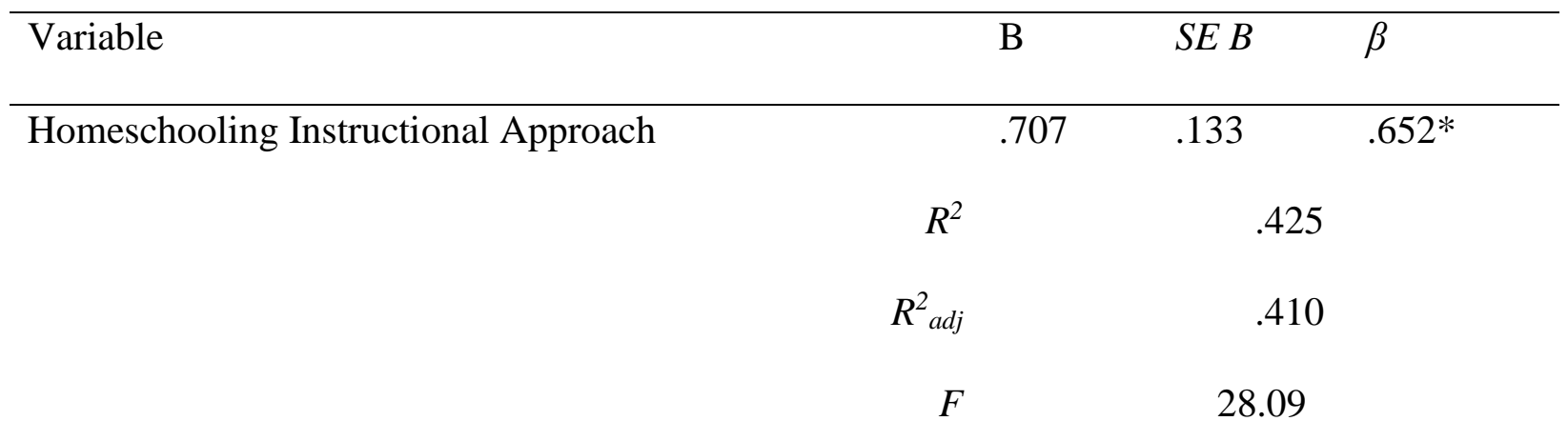

Note. An $*$ indicates significance at $p<.05(n=40)$.

For parents and RQ8, the simple regression indicated that $23.5 \%$ of the variance in parent-child closeness was positively predicted by instructional approach, $R^{2}{ }_{a d j}=.222, F(1,58)=$ $17.79, p<.001$. Missing cases were excluded pairwise. More specifically, the significant results of the regression procedure indicated that parent's instructional approach positively predicted a significant amount of variance in parent-child closeness. Analysis of regression coefficients indicated the instructional approach, $\beta=.485, t=4.21, p<.001,95 \%$ CI $[.39,1.10]$ significant predictor for parents. The parent-child closeness and instructional approach did not produce Tolerance or VIF statistics indicating collinearity. See Table 21 for parent beta weights.

RQ9 asked if conversation orientation would predict parent-child closeness. Missing cases were excluded pairwise. For students, the simple regression indicated that $66.6 \%$ of the variance in parent-child closeness was positively predicted by conversation orientation, $R^{2} a d j=$ $.657, F(1,38)=75.62, p<.001$. The significant results of the regression procedure indicated that conversation orientation positively predicted a significant amount of variance in parent-child closeness. Analysis of regression coefficients indicated the conversation orientation, $\beta=.816, t=$ $8.69, p<.001,95 \%$ CI $[.63,1.02]$ was a significant predictor for the students. The parent-child 
closeness and conversation orientation did not produce Tolerance or VIF statistics indicating collinearity. See Table 22 for beta weights.

\section{Table 21}

Beta Weights for Instructional Approach Predicting Parent Relational Closeness

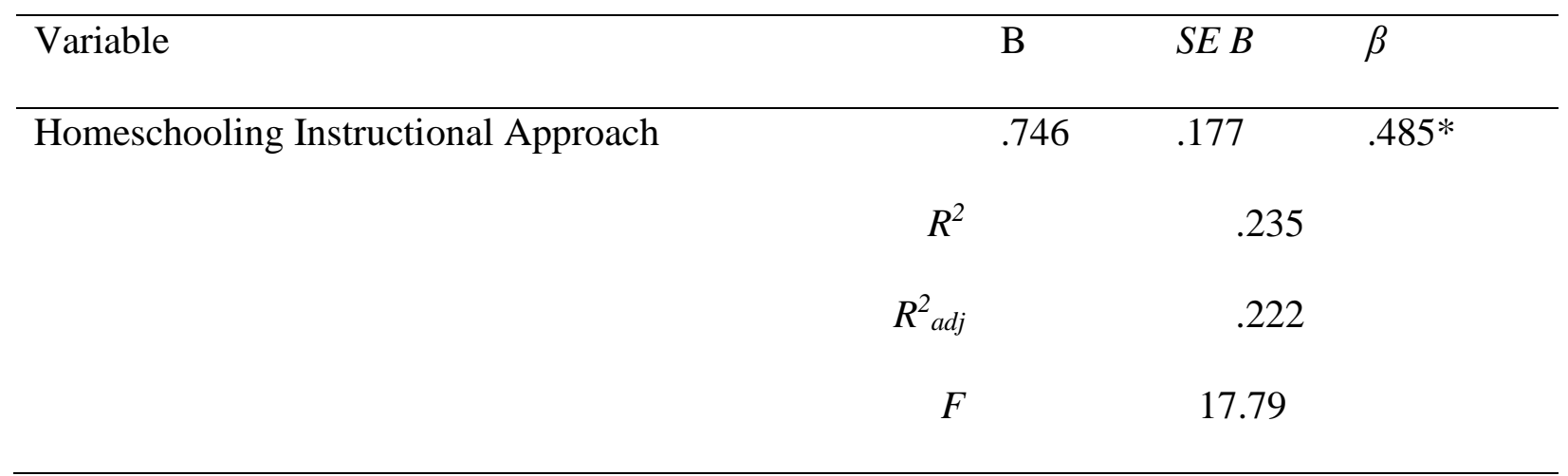

Note. An $*$ indicates significance at $p<.05(n=60)$.

\section{Table 22}

Beta Weights for Student RFCP Predicting Relational Closeness

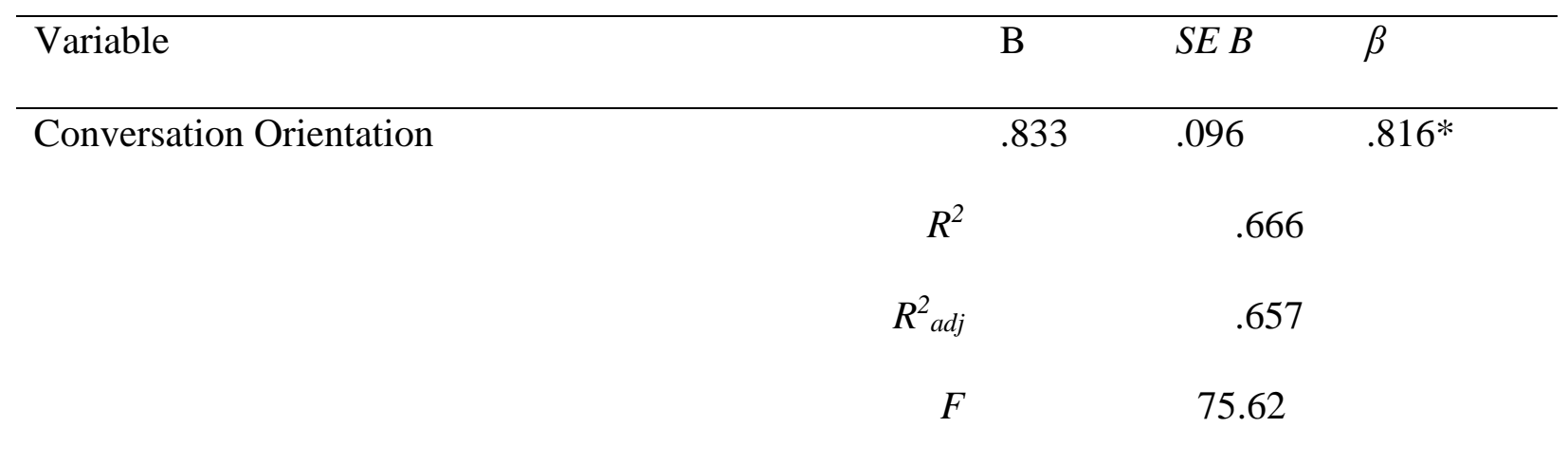

Note. An $*$ indicates significance at $p<.05(n=40)$.

For RQ9, a simple regression was also run with parent responses, and the results indicated that $27.0 \%$ of the variance in parent-child closeness was positively predicted by conversation orientation, $R_{a d j}^{2}=.258, F(1,58)=21.48, p<.001$. Missing cases were excluded 
pairwise. Results are shown in Table 23. The significant results of the regression procedure indicated that conversation orientation positively predicted a significant amount of variance in parent-child closeness. Analysis of regression coefficients indicated the conversation orientation, $\beta=.520, t=4.63, p<.001,95 \%$ CI $[.41,1.05]$ was a significant predictor for parents. The parent-child closeness and conversation orientation did not produce Tolerance or VIF statistics indicating collinearity.

Table 23

Beta Weights for Parent RFCP Predicting Relational Closeness

\begin{tabular}{lcccc}
\hline Variable & B & SE B & $\beta$ \\
\hline Conversation Orientation & & .738 & .159 & $.520^{*}$ \\
& $R^{2}$ & .270 & \\
& $R_{\text {adj }}^{2}$ & \multicolumn{2}{c}{.258} & \\
& $F$ & 21.48 &
\end{tabular}

Note. $\mathrm{An} *$ indicates significance at $p<.05(n=60)$.

RQ10 asked if conformity orientation would predict parent-child closeness. A simple regression procedure investigated if conformity orientation could predict parent-child closeness. Missing cases were excluded pairwise. From the student perspective, results indicated that $18.5 \%$ of the variance in parent-child closeness was negatively predicted by the student ECOS, $R_{a d j}^{2}=$ $.163, F(1,38)=8.62, p<.006$. The significant results of the regression procedure indicated that conformity orientation negatively predicted a significant amount of variance in parent-child closeness. Analysis of regression coefficients indicated the conformity orientation, $\beta=-.430, t=$ $2.93, p<.006,95 \%$ CI $[-.69,-.12]$ was a significant predictor for parents. The parent-child 
closeness and conformity orientation did not produce Tolerance or VIF statistics indicating collinearity. See Table 24 for beta weights.

\section{Table 24}

Beta Weights for Student ECOS Predicting Relational Closeness

\begin{tabular}{llrrr}
\hline Variable & $\mathrm{B}$ & \multicolumn{1}{l}{$S E B$} & $\beta$ \\
\hline Conformity Orientation & & -.413 & .141 & -.430 \\
& $R^{2}$ & .185 & \\
& $R^{2}{ }_{a d j}$ & .163 & \\
& $F$ & \multicolumn{2}{c}{8.62} &
\end{tabular}

Note. An * indicates significance at $p<.05(n=40)$.

Like all the research questions, RQ10 also required a regression to be run to parent data. Missing cases were excluded pairwise. As shown in Table 25, results of the simple regression indicated that $1.5 \%$ of the variance in parent-child closeness was not predicted by the parent ECOS, $R^{2}{ }_{a d j}=-.20, F(1,58)=.86, p=.35$. The non-significant results of the regression procedure indicated that conformity orientation did not predict a significant amount of variance in parent-child closeness. Analysis of regression coefficients indicated the conformity orientation, $\beta=.121, t=.93, p=.35,95 \% \mathrm{CI}[-.13, .36]$ was not a significant predictor for parents. The parent-child closeness and conformity orientation did not produce Tolerance or VIF statistics indicating collinearity. 


\section{Table 25}

Beta Weights for Parent ECOS Predicting Relational Closeness

\begin{tabular}{|c|c|c|c|}
\hline Variable & B & $S E B$ & $\beta$ \\
\hline \multirow[t]{4}{*}{ Conformity Orientation } & .116 & .125 & $.121 *$ \\
\hline & $R^{2}$ & .015 & \\
\hline & $R_{a d j}^{2}$ & -.002 & \\
\hline & $F$ & .868 & \\
\hline
\end{tabular}

Note. An $*$ indicates significance at $p<.05(n=60)$.

Correlation analysis was run to explore the data that was obtained across the five scales used in the survey. The results indicated that for students, all 10 bivariate correlations were statistically significant, see Table 26. The highest correlation for students was between conversation orientation and closeness, meaning conversation orientation has the largest impact on student perceptions of closeness to their parent.

\section{Table 26}

Correlations among Scales for Student Reported Data

\begin{tabular}{|c|c|c|c|c|c|c|c|c|}
\hline Variable & $n$ & $M$ & $S D$ & 1 & 2 & 3 & 4 & 5 \\
\hline 1. Student Relational Satisfaction & 39 & 2.67 & .51 & - & & & & \\
\hline 2. Student Relational Closeness & 40 & 4.21 & .90 & $.80 * *$ & - & & & \\
\hline 3. Student Instructional Approach & 43 & 3.82 & .83 & $.60 * *$ & $.65 * *$ & - & & \\
\hline 4. Student RFCP & 42 & 3.56 & .88 & $.66 * *$ & $.81 * *$ & $.71 * *$ & - & \\
\hline 5. Student ECOS & 40 & 5.08 & .94 & $-.38 *$ & $-.43 * *$ & $-.35 * *$ & $-.53 * *$ & - \\
\hline
\end{tabular}


For parents, the results found that only five, which is half, of the correlations were statistically significant, see Table 27. The data shows that for parents, the highest correlation was between conversation orientation and homeschooling instructional approach, meaning that for parents, conversation orientation had the largest impact on their instructional approach.

\section{Table 27}

Correlations among Scales for Parent Reported Data

\begin{tabular}{|c|c|c|c|c|c|c|c|c|}
\hline Variable & $n$ & $M$ & $S D$ & 1 & 2 & 3 & 4 & 5 \\
\hline 1. Parent Relational Satisfaction & 60 & 2.78 & .37 & - & & & & \\
\hline 2. Parent Relational Closeness & 60 & 4.46 & .74 & $.44 * *$ & - & & & \\
\hline 3. Parent Instructional Approach & 72 & 4.42 & .48 & $.30^{*}$ & $.48^{* *}$ & - & & \\
\hline 4. Parent RFCP & 66 & 4.20 & .52 & .19 & $.52^{* *}$ & $.58^{* *}$ & - & \\
\hline 5. Parent ECOS & 64 & 4.38 & .77 & -.02 & .12 & .24 & -.04 & - \\
\hline
\end{tabular}

\section{Results Summary}

The 10 research questions that were ultimately run show interesting trends among the student and parent data. Of the research questions presented, student data produced significant relationships for all eight questions, meaning that when it comes to homeschooling, instructional approach, conversation orientation, conformity orientation, relational satisfaction, and closeness are all interconnected. However, the results of the eight research questions tell a different story for parents. For parents, only half of the questions produced significant relationships, meaning that for parents, factors such as conversation and conformity do not play the same role with reference to homeschooling instructional approach, relational satisfaction, and closeness, the way 
those orientations did for students. The next chapter will provide an in-depth discussion of the results. 


\section{CHAPTER IV: DISCUSSION}

The primary goal of this study was to explore how relationships within the homeschooling environment are impacted by the way students and parents communicate with one another. Further, the goal was to explore how communication impacts instructional approach, relational satisfaction, and relational closeness. A quantitative survey, using closeended questions, was shared with students and parents who had previous homeschooling experience through a convenience and then snowball sample. The results of this study add to the robust body of family communication pattern literature and shed light on relational satisfaction and closeness. Conversation orientation emerged as an important factor for students and parents regarding instructional approach, relational satisfaction, and closeness. Conformity orientation did not seem to matter as much for students, and almost not at all for parents. These findings are consistent with previous family communication research, but the homeschool environment provided a unique setting to dive deeper. Overall, the results are thought-provoking and provide interesting insight not only into how communication makes a difference, but who it makes a difference for. The goal of this chapter is to address the findings of the research questions, implications, limits, and suggestions for future research.

\section{Summary of Findings}

The goal of this study was to explore communication patterns within a homeschooling setting between children who were homeschooled and parents who provided, or still provide, homeschooling. RQ1 asked if conversation orientation would predict parents' homeschooling instructional approach. For students, half of the variance in instructional approach was predicted by conversation orientation. This means that for half of the student respondents, conversation orientation did impact their instructional approach. Although the survey did collect and report 
student data for RQ1, the students were reporting on their parents. For RQ1, parent response data is more important, because the parents were self-reporting. The results found that for a significant amount of parent participants, conversation orientation did impact their instructional approach, in a positive, student centered way. This means that for parents with high conversation orientation, they lean toward more student-centered homeschooling approach, this result is consistent with previous literature and aligns with the idea that student-centered learning is the most effective (Goodyear \& Dudley, 2015). These data show us that conversation orientation does play a significant role; in this case for half of student participants and one-third of parent participants.

RQ2 asked the next logical question through the RFCP lens, which was, "Will conformity orientation predict parents' homeschooling instructional approach?" After such strong results for conversation orientation, data surprisingly showed that for students, conformity orientation did not matter as much for students or parents. Once again, as with RQ1, the second research question also collected student responses and those student data are reflective of perceived parental conformity orientation and instructional approach. Although those data are good to have, it is not self-reported; therefore, the parent data may be more revealing. This is noteworthy because the data for RQ2 suggests that conformity orientation has a much smaller impact on the instructional approach, whereas conversation orientation had a measurable impact. This is important because both conversation and conformity orientation are part of the RFCP, so it seems the results are similar to the conversation orientation results.

RQ3 was intended to be analyzed with an independent-samples $t$-test but, in the end, the child and parent surveys wound up using different items. After eliminating scale items based on EFA, different items were eliminated for each group, resulting in slightly different surveys. 
Conceptually, the surveys were the same, but in actuality, they were not. While both student and parent data had mean scores above the midpoint, parents did seem to evaluate their relationship satisfaction more positively than the student participants. While the survey data does not tell us why students fail to rate relationship satisfaction higher, the data does help tell a story. It could be that students see their parents as an authoritative figure, which can hinder relational satisfaction. Homeschool students, who have their parent serving in the dual role of parent and educator could complicate the relationship, thus impacting overall relational satisfaction. Parent data shows that overall, parents look at their relationship with their child in a more positive light.

RQ4 examined instructional approach again, but this time to see if it could predict parentchild relational satisfaction. For students, the results indicated that instructional approach did have a significant impact on relational satisfaction. Previous studies on instructional styles have found that student-centered instruction contributes or a positive learning environment (Garrett, 2008). For parents, results also revealed a variance in relational-satisfaction based on instructional approach, but it was considerably less compared to student responses. This is a very important piece of information for homeschool families to consider, these results indicate that how students are homeschooled and how instruction is provided makes a difference in how satisfied they are with the relationship with their parent. Additionally, all student participants were over 18 and had been finished with homeschool for at least one year, meaning that the impact of instructional approach has a lasting impact on relational satisfaction beyond homeschooling, not just in the moment of it.

RQ5 investigated the RFCP and asked if conversation orientation would predict parentchild relational satisfaction. Results for students showed that conversation orientation mattered significantly for their relational satisfaction. This result is consistent with previous research that 
has shown that a child's perceived conversation orientation within their family is positively associated with their satisfaction in their parent-child relationships (Baxter \& Pederson, 2013). This result shows the importance of conversation within a family and that high conversation orientation has a direct impact for almost half of student respondent's relational satisfaction. This finding aligns with a similar study that concluded, "when parents create family climates that foster frequent candid conversation between family members during emerging adulthood, children experience their relationships as more satisfying" (Aloia, 2016, p. 87). The student results stress the importance of high conversation and the open exchange of ideas and opinions. When children feel valued and respected, they are more satisfied in their relationships. Previous research has shown that expressiveness has a strong, positive association with family strength (Schrodt, 2009). Surprisingly, for parents, the reported data did not show a significant link between conversation orientation and relational satisfaction, revealing that conversation was more important for the student participants of this study than the parents. Parents may report relational satisfaction regardless of their conversation orientation.

RQ6 explored the other component of RFCP, conformity orientation, and its impact on relation satisfaction. Again, it mattered more for students than parents, but the mean scores were low for both groups. This is also consistent with a previous study that discovered a child's perceived conformity orientation was not significantly related to relational satisfaction (Baxter \& Pederson, 2013). While the results were lower for conformity orientation, compared to conversation orientation, it is still important to unpack why. One possible explanation is that family members who are high in conformity orientation are less likely to participate in relationship maintenance behaviors because conformity orientation does not encourage or discourage relationship sustaining communication patterns (Aloia, 2016). This does not mean 
that high conformity families cannot be close or satisfied in their relationships, it merely means that the communication style does not place the same importance on relationships. When children leave the home and have fewer shared tasks with their parents, they have fewer reasons to talk because the relationship was not built on communication (Baxter \& Pederson, 2013). Relationships are about communication and compromise and for this study, children who fall into high conformity families that stress relationships of obedience and conformity over the exchange of ideas may not be satisfied in their parent-child relationships. Protective families do not share emotions and experiences on a regular basis (Koerner \& Fitzpatrick, 2002a) and this result shows us that environment could be problematic for relational satisfaction. Though low compared to other results, this data is important because it shows that more open communication patterns will equal more satisfied children.

RQ7 was intended to be independent-samples $t$-test but the child and parent surveys wound up not being the same in the end, so the test could not be run as intended. After eliminating scale items, different items were eliminated for each group, resulting in slightly different surveys. Conceptually, the surveys were the same, but in actuality, they were not. Parents had slightly higher means than students' perceptions of closeness, but they were still around the midpoint, with parents scoring slightly higher. Although the data does not directly address the reasons why, it is again possible that the dual role parents serve as parent and educator can have a negative impact on relational closeness. Students may desire a break from their parent; the constant time together during the school day and free time spent together could be too much. It is also possible that the lack of paired data could be the problem. Maybe this particular group of students and parents scored closeness this way, but perhaps paired data would 
have told a different story. Regardless of the possible reasons why, the current data demonstrates that parents tend to scale their relationship in a more favorable light than students.

RQ8 explored whether parents' homeschooling instructional approach would predict parent-child closeness. For both students and parents, the results produced significant relationships among the variables. These significant results align with research on the positive effects of student-centered learning. This finding is important because it demonstrates that the style of instruction used in homeschool impacts feelings of closeness. In student-centered classrooms the importance is placed on shared leadership, community building, and a balance between the needs of the students and the teacher (Garrett, 2008). All those characteristics of a student-centered classroom are deeply rooted in strong, collaborative communication, which leads to better relationships, and therefore increased closeness. This finding aligns with previous research that demonstrated that parental involvement is important in student's school careers (Barwagan et al., 2004). Relational closeness is best explained as the maintenance behaviors and effort put forth to demonstrate the overall quality of a relationship; it is different from satisfaction because it is related to relational fulfillment. Closeness equates to warmer feelings and a stronger relationship (Wang et al., 2018), and this data shows how important instructional strategy is in ensuring those warm, strong feelings.

RQ9 examined closeness again, but this time with family communication patterns. RQ9 asked if conversation orientation would predict parent-child closeness. This response produced the greatest significance, with $66.6 \%$ of students reporting a strong link between conversation orientation and feelings of parent-child relational closeness. Previous work supports this finding, too. For instance, Golish (2000) found that a lack of communication can be associated with a substantial decrease in feelings for closeness. For parents too, conversation orientation and 
closeness were aligned. Golish also found that in their participant's definition of closeness, open communication was included. These significant results suggest that high conversation orientation equals relational closeness. In the study, Golish found that participants included open communication as part of their definition or closeness which supports the results of this study. Pluralistic families that engage in low conformity and high conversation who exchange ideas report higher levels of closeness. This aligns with previous research that pluralistic families, or those that have low conformity and high conversation, encourage all family members to be involved (Horstman et al., 2018) which shows that the more people feel involved and invested, the closer they are.

RQ10 asked if conformity orientation, the other aspect of RFCP, would predict parentchild relational closeness; and, it did for students but not for parents. Overall, the mean scores for conformity orientation were lower for students and for parents, than conversation orientation, as they were in RQ6 when the study examined conformity orientation and satisfaction. In low conversation settings, parents are less open about their emotions and they are less likely to encourage their child to be expressive about their feelings (Kelly et al., 2002). This information once again stresses that families high in conformity run the risk of having relationships that are not as close. Overall, the impact of conformity, which was also demonstrated in the results of RQ6, is not as significant as conversation orientation, but it does make a difference to students.

\section{Implications}

\section{Practical Implications}

The current study offers practical implications for families in both homeschooling and non-homeschooling environments because communication is at the forefront. In this study, the findings demonstrate the positive impact high communication orientation has on relational 
satisfaction and closeness for students. The results of RQ5 and RQ9 provide evidence that students feel connected with their parents through communication, and through that communication they are more likely to feel relational satisfaction and closeness with their parents. All families have problems, but conflict can be stabilized through communication (Guan \& Li, 2017). Although results of the current study provide data regarding a very specific communication relationship and environment, the results can be applied in larger scale.

For students, the results highlight the importance of communication and the role it plays in relational satisfaction and closeness. Past studies have clearly indicated that conversation orientation is positively associated with face-to-face and online relational maintenance behaviors and conformity orientation is inversely association with face-to-face relational maintenance (Ledbetter, 2009). High conversation orientation families are helping equip students with the communication skills and confidence to build and maintain relationships. If parents do not model open communication through discussions about their feelings and emotions, children are likely to mimic that behavior (Kelly et al., 2000).

For parents, this research is important because it explores FCP theory in an unique communication setting. Parents should take note of how crucial communication is within their family, as the results clearly demonstrate. Open, honest, engaging communication that allows for children to learn, grow, and explore, is the best route. Not only does this type of communication promote leadership and independence, it helps students feel trusted, valued, and closer to their family. The confidence built in high-conversation families can lead to success throughout life. Observations from previous research has found that the adjustment to college life is more challenging for high-conformity orientation families, and they may have trouble with similar life adaptions and report higher levels of apprehension (Kelly et al., 2002; Ledbetter, 2009). 
Therefore, one could speculate that trouble adapting to new situations as well as increased levels of apprehension could impact student's feelings of satisfaction and closeness. Parents can use this knowledge to empower their students to have highly communicative families for lasting bonds.

Most communication studies regarding school take place within traditional education settings that involve a teacher instructing a classroom full of students. For homeschool organizations and cooperatives this study provides insight specifically into homeschooling families. By working specifically within the homeschooling environment, the present study demonstrated the importance of open communication on overall relational satisfaction and closeness. Homeschool organizations and cooperatives can encourage parents to foster environments where students are empowered and involved in learning. Empowering students will allow for parents and students to both feel valued, and it will help improve their relationship long term. Homeschool families spend the entire school day together and applying an open communication approach can help maximize that time together for education and relational purposes.

In the classroom setting, teachers work with students using a variety of direct and indirect instructional behaviors to enhance student learning (Goodyear \& Dudley, 2015). Stifling communication can cause children to feel like their viewpoint does not matter, which can stifle creative and independent thinking. For homeschool families, high communication patterns can help parents and students work together to increase student engagement and learning. With homeschooling, it should be noted that parents, generally speaking, enter homeschooling voluntarily while children may or may not enter homeschooling voluntarily. This distinction is important because it makes relationship building and maintenance more crucial since the 
relationship is familial. For educators, this relationship aids student success, but for parents who homeschool, they have the additional benefit of a stronger parent-child bond. This is noteworthy for homeschool families but can also be applied to families whose children leave to go to school every day. Teaching children to be independent thinkers encourages students to participate and engage in lessons.

At the very beginning of this thesis, the COVID-19 pandemic and the impact it has had on education was addressed; it is worth revisiting this discussion. COVID-19 has changed the way the world looks at education and the delivery of it. Many school districts have utilized remote learning during the 2020-2021 school year, or some form of blended learning which incorporates both in-person and remote learning. Whatever the case, this study has demonstrated the true importance of communication within families and how high communication generally is related to higher relational satisfaction and closeness. For families that are experiencing remote learning, or homeschooling, the most important insight this study can provide is to communicate openly.

\section{Theoretical Implications}

The present study has theoretical implications as well, most notably for family communication, in particular regarding RFCP and ECOS, instructional communication, relational satisfaction, relational closeness and — although not anticipated - Communication Privacy Management (CPM). In all instances, the importance of communication resonates throughout the results and implications, highlighting that families should focus on developing high communication patterns that allow for all family members to be involved in the learning process. Open communication will allow for deeper relationships, understanding, emotional intelligence, and lasting impressions of relational satisfaction and closeness. 
First, and most crucially, are the implications this research has for family communication patterns theory (FCPT) and the use of RFCP and ECOS scales. Research in family communication patterns has shown how the overall communication climate within a family can affect relationships (Shebib, 2020), and the findings of the present study were no different. High conversation orientation was positively associated with relational satisfaction and closeness for both students and parents, but students still rated these higher. Consistent with expectations, a family with high conversation would generally feel more satisfied and report higher levels of closeness. Thus, the present findings are consistent with previous research that suggests children who grow up in high conversation orientations tend to have better skills to manage relationships with confidence (Koesten \& Anderson, 2004). Pluralistic families are those that are high in conversation and low in conformity. They are a highly independent family where members ideas are exchanged, and discussed (Koerner \& Fitzpatrick, 2002b). In a homeschool environment, the open communication and open exchange of ideas regarding education and learning are all tied to the foundations of FCPT. While RFCP was initially one large scale that measured both conversation and conformity, the ECOS does a better job at measuring conformity, and the present study can further vouch for the utility of ECOS.

The ECOS was developed to overcome drawbacks of the initial conformity measure that was used in the RFCP (Horstman et al., 2018). Originally, the conformity measures within the RFCP were oversimplified, and did not provide a full picture of conformity orientation (Koerner $\&$ Schrodt, 2014). Consistent with the idea that conversation and conformity orientation are inversely related, the results of this study agreed. Four research questions were used to explore the relationships between conversation and conformity orientation with relational satisfaction and closeness. Conversation orientation proved to be a significant factor for satisfaction and 
closeness, while conformity orientation was not, supporting the inverse relationship conversation and conformity have. Therefore, when conversation orientation scores were high, the conformity orientation scores for those same questions scored low, as was displayed in the results. Consequently, communication plays an important role in fostering satisfaction and closeness among parents and students in a homeschool environment. Consistent with previous research, parenting is all about a Goldilocks approach of conversation and conformity, parenting is a delicate balance between leniency and control (Givertz \& Segrin, 2014). This delicate balance also spills over into educational theory.

Consistent with the literature, parental involvement appears to be related to academic achievement for homeschooling families. While the present study did not ask for grades or class ranks, student participants connected conversation orientation to their homeschooling instructional approach very highly. There was a slider question that asked participants to rate on a 100-point scale, how well homeschool prepared students for the future. This question received favorable responses, suggesting the high conversation approach can lead to well-prepared children. Parental involvement has been found to be an important factor in academic achievement and parents should communicate their involvement with their child (Barwagen et al., 2004). While this study focused specifically on homeschool students and parents, the findings can be applied on a broader scale. Even students that attend a traditional school environment benefit from engaged parents at home. The implications for the learner-centered approach to education expands beyond the scope of this study and provides implications for parents and teachers alike.

The learner-centered approach allows the student to take control of their learner rather than passively absorb (Brown-Wright, 2011). Developing students in a way that they are active 
in their learning and discovery is important not only for learning but for relationships as well. Homeschooling families have time and flexibility to spread lessons out over longer-or shorter - periods of time based on the needs of their individual student, whereas traditional classrooms must work at a pace for the whole. Parents that want to engage more in their child's learning can apply more conversation tactics to help grow and enhance their child's development outside of the classroom.

Relational satisfaction is measured by how one feels about their overall relationship with another person. Results of this study indicate that conversation plays a large role in relational satisfaction for students while conformity also plays a role, albeit a much smaller one than conversation. Thus, conversation is important for relationship satisfaction, because there must be a level of relational maintenance, which is voluntary behaviors and acts used to show the level of satisfaction (Ledbetter \& Beck, 2014). Typically, with homeschooling, the parent has the power because it can be assumed, they made the decision to homeschool, whereas the child may not have had a say in the matter. The present study examined former homeschool students, which is a key feature of the study, because the participants are not currently in the role of homeschool student, yet they still rated conversation orientation as a high predictor of relational satisfaction. Thus, we can assume that the participants are currently participating in maintenance behaviors because they are satisfied with their relationships, which should mean they come from high conversation orientation families. Expressiveness has a strong, positive association with family strength (Schrodt, 2009) and expressiveness is cultivated by conversation, which allows us to infer that these families are not only communicating frequently and openly, they are strong. Relational closeness, which deals with daily interactions and effort, also deserves a closer look. 
Relational closeness refers to the quality of affection as well as daily relationships among family members. Closeness deals with warmth and involvement (Strage, 1998). Conversation orientation had a direct and strong correlation with closeness in this study. While conversation and conformity orientation did play a role in the research questions regarding instructional approach and relational satisfaction, they did not compare to the results that involved closeness. For two-thirds of student participants, and over one-quarter of parents, conversation orientation had a positive correlation to parent-child closeness. This data is crucial because it allows us to infer that more than anything else, communication equals closeness. Closeness deals with the day-to-day relationships, but this study dealt with former homeschool students, demonstrating how the power of communication can span gaps in time and keep people close. Constant daily communication, joking around, relationship talk, and sharing life experiences demonstrate that families who talk are generally happier (Burns \& Pearson, 2011). The findings on closeness truly drive home the reoccurring theme that conversation matters. Not only did this research provide the anticipated theoretical implications for FCPT, instructional communication, satisfaction and closeness, but it provided unexpected implications for CPM theory.

Privacy management does play a role in the homeschool family because families use privacy to decide to whom they disclose, and for what purpose. Privacy disclosure is dependent on motivation and relationship quality (Hammonds, 2015). A previous study on CPM found that the family relationship culture positively predicts a child's likelihood to disclose private information to their parents (Hammonds, 2015). It is important for homeschool students and parents to feel that their privacy is safe; otherwise, it could cause breakdowns in family relationships and student learning (Padilla, 2020). Family communication is influenced by factors such as hierarchy, cohesiveness, and competence; and high communication families 
could be the best environment for homeschool students, since their interaction to the outside world can be a bit more limited. For example, if a homeschooled student is struggling emotionally and they do not have access to a guidance counselor, the way that a public-school child does, the homeschooled student needs to feel confident enough to talk to their parent or at least tell them what they need to get help. Public school students have free access within their educational programming to school counselors, resources offices, and therapists. Plus, they can access those resources by either requesting services or by being referred for services. Generally, it is a seamless process and families are not charged for these services. All families, but especially those homeschooling, should pay attention to how interconnected communication is to the overall emotional and mental health of their students.

Overall, the present study was one of the first, if not the first, to examine homeschooling relationships between children and parents through the lens of FCPT and the impact on instructional approach, satisfaction, and closeness, which pushes the boundaries of communication education literature. Not only does this exciting data allow us to see new ways to apply existing theories, it also provides insight into how these theories can be pushed beyond their current applications. Most studies regarding communication education assume a traditional setting where children go to school and are educated by teachers, whereas this study addresses students staying home to be educated by their parents. This demonstrates how the existing framework of our current theories needs to be expanded and applied to smaller niche groups to see how the theories perform in different environments.

\section{Limitations}

The present study produced informative and thought-provoking data on communication and parent-child relationships within the homeschool environment. However, the study was not 
without limitations and those limitations need to be addressed in future studies that work with similar participant populations. Four prominent limitations can be identified: lopsided data, unpaired data, low response rate, and unreliable scales. The following paragraphs will dissect these limitations and how they may have impacted the results.

First and foremost, the data was lopsided. The survey had 38 usable student responses and 55 usable parent responses. Second, the data was not paired, so the responses of strangers were being compared, whereas surveying a former homeschool student and their parent that provided them with their homeschool experience could have produced different results. By not pairing the data, responses came from a wide variety of experiences which could have had a strong influence on the results. Not only were the numbers lopsided, they were low, which was another limitation.

Third, this study yielded 93 usable responses total, which is not a very large data pool. This study was met with hesitation from the homeschool community, and understandably so, considering they often face stigma. The fear of participating could be rooted in the concern that the study could have presented homeschool families in a negative light, therefore limiting the potential of this study. With more participants, and endorsement of more local or national homeschool organizations, the results of the study could have been more balanced regarding student and parent participation. Future researchers will need to thoroughly explain the purpose of their study and have a stronger backing of support and endorsement from the homeschool community to help gain a larger participant pool. While the small number of participants is a weakness of the present study, it should be noted that the survey was left open for over two months, with multiple reminders and requests to share. Due to the limited population this survey was seeking, it is impossible to determine how many more participants this survey could have 
realistically attracted, given the specific requirements set forth. The current study not only lacked participants; it lacked reliable scales.

Although the RFCP and ECOS performed exactly as they should, considering they are frequently used and cited, the scales developed for this survey did not perform as well. The fourth limitation of this study was the three scales: Homeschooling Instructional Approach Scale, the Modified Relational Satisfaction Assessment Scale, and the Modified Relational Closeness Scale. The instructional approach scale was made from scratch for this study and while it shows promise, it started with 20 items and had to be paired down to 15 for students and five items for parents to produce an acceptable one-factor solution. This meant that student and parent responses were not compared apples to apples and would need significant work to be used again in a reliable way. The Modified Relational Satisfaction Assessment Scale also had its struggles, starting off as a five-question scale but wound up being a four-question scale for students and a three-question scale for parents. For parents, the question, "How much do you love this child?" proved to be problematic. It was eliminated but could have also been off-putting to some parent respondents. Finally, the Modified Relational Closeness Scale started off as a 10-item scale but was paired down to eight items for students and three items for parents. The pairing down of scales meant that in the data, the responses were not being compared equally and students and parents wound up answering different questions. The low number of participants also made it difficult to test scale reliability, had there been a greater response, it is possible that the scales would have performed better. These scales need to be greatly revised or replaced with more reliable scales. The scales were problematic because in some cases they may have presented a bias, but bias could also have come through due to self-reporting. 
Finally, a limitation of this study is that it relied on self-reported data. Students reported about themselves and parents reported about themselves. Considering this population is accustomed to being stigmatized and criticized by practitioners of more traditional education styles, there could have been a level of social-desirability bias, especially among the parents. No one wants to feel attacked for their educational choices or resources, but for parents, negative data on homeschool could also feel like a negative assessment on parenting. Although this study had its fair share of limitations, those limitations do not negate the important findings, and they can be addressed in future research.

\section{Suggestions for Future Research}

Most importantly, future research needs to have a strong endorsement from a larger homeschool community so that a larger sample size can be used. The greatest point of weakness for this study was the low number of responses. Although homeschooling is growing in popularity, it is still a niche group in education, and it can be difficult to get through. In order to get the support of the homeschool community future research may need to be done in collaboration with a homeschool organization or presented to a local group at a cooperative meeting or gathering so that families fully understand the goals. Perhaps a longitudinal research or ethnographic methods would help build trust and produce increased response rates. It is possible that some qualified candidates chose not to complete this survey out of fear of further stigma. In addition to easing the minds of potential participants, the survey scales need revision.

The second recommendation for future researchers is to use existing, tested scales that will not need to be altered as much in the data examination. As discussed in the limitations, survey itself was not without issues. Many of the scales needed to be paired down in different ways which made comparing data difficult. Due to the inconsistencies in the scales, the results 
do not compare student and parent responses question to question, which was the ideal outcome. Additionally, because the homeschooling group is hard to get to, when there is an opportunity to connect, it is important to make the most of that opportunity and collect all the data possible. Future researchers could also explore different data collection methods.

One such method that could be beneficial for future research would be collecting paired data, which would be the third suggestion for future research. Surveying parents and children from the same household could result in more consistencies and greater reliability. Additionally, researchers could perform a mixed-method study wherein quantitative and qualitative data are explored using the same sample. Focus groups, interviews, or even case studies seem to be promising methods as they would require at least mild relationship building and trust for participation. Interviews with even a portion of the respondents could provide insight and direction into how data landed where it did. Homeschooling families are not easily accessible or observable which creates challenges in studying these families. Going forward, this research provides a strong starting point, but there is much left to be discovered.

Future researchers need to explore family communication patterns within homeschool environments and traditional school environments between parents and children. Comparisons can be drawn from the different groups to examine differences in communication styles between families and overall reports of satisfaction and closeness. Findings can help inform all families, regardless of their instructional choice, on the best way to create happy relationships. Future researchers should also explore the usefulness of a qualitative approach so that deeper understanding and meaning can be applied to data points. Interviews and focus groups would be a great way to uncover deeper-level data and implications. This same group could also be studied through different lenses. 
One such way to expand on this line of research in the future would be an evaluation through an educational lens. The goal of this research was to explore family communication within the homeschool dynamic, but homeschooling can also be explored in other ways. What the Homeschooling Instructional Approach Scale attempted to do was determine if students' homeschooling education environment was more learner-centered or instructor-centered, but as the limitations point out, it was not a reliable measuring stick. Future researchers can either revise this scale to make it reliable or use other existing scales that measure learner-centered and instructor-centered classrooms to uncover patterns that emerge among homeschool. The number slider question that asked how much they felt homeschool prepared them for the future could also be another study, and not just for homeschool. Data could be used from public education students and homeschool students to draw comparisons and patterns.

Finally, future research on homeschooling should explore the element of choice. Choosing to homeschool is generally a decision made by parents, and children may or may not want to be homeschooled. This is different than the typical student's public-school experience, where students leave for school each day. Future researchers should ask homeschooling participants how they feel about being homeschooled, if they had a say in it, and what led them to homeschool. It seems that these factors could all play a role in variables such as academic achievement, educational approach, and family relationships. This study provides a wide variety of areas to explore and is just the beginning for homeschool research within the field of communication.

\section{Conclusion}

The present study adds to the existing literature on RFCP, instructional communication, relational satisfaction, relational closeness, and CPM. The aim of this thesis was to explore 
family communication patterns within the homeschool environment and how those patterns influenced variables such as instructional approach, relational satisfaction, and closeness. A closed-ended quantitative study gathered participants through snowball and convenience sampling and yielded a respectable number of responses for this niche educational community. Family communication orientations impacted how homeschool students and parents rated their feelings of relational satisfaction and closeness with one another. The student responses were more drastically determined by conversation and conformity orientation than the parents' responses, but both did see movement in both areas. Future researchers should use this study as a springboard to explore homeschooling and resist assuming the traditional school setting comprises the only educational group worthy of study. The key takeaway from this study is that communication is critical for successful familial relationships. Conversation orientation proved to be the single most important factor for students regarding their feelings of relational satisfaction and closeness, demonstrating that communication is key, especially when education takes place at the kitchen table. 


\section{REFERENCES}

Ahmed, A., \& Ahmed, N. (2017). Comparative analysis of rote learning on high and low achievers in graduate and undergraduate programs. Journal of Education and Educational Development 4(1), 111-129. https://doi.org/10.22555/joeed.v4i1.982

Alt, D. (2016). Using structural equation modeling and multidimensional scaling to access female college students' academic adjustment as a function of perceived parenting style. Current Psychology 35(4), 549-561. https://doi.org/10.1007/s12144-015-9320-3

Anthony, C. J., \& Ogg, J. (2019). Parent involvement, approaches to learning and student achievement: Examining longitudinal mediation. School Psychology, 34(4), 376-385. https://dx.doi.org/10.1037/spq0000282

Bartholomew, K., \& Horowitz, L. A. (1991). Attachment styles among young adults: A test of a four-category model. Journal of Personality and Social Phycology, 61(2), 226-244. https://doi.org/ 10.1037/0022-3514.61.2.226

Barwagen, L. M., Falciani, N. K., Putnam, S. J., Reamer, M. N., \& Stair, E. E. (2004). Academic achievement of homeschool and public-school students and student perceptions of parental involvement. The School Community Journal, 14(1), 39-58 https://www.adi.org/journal/ss04/Barwegen,\%20et\%20al.pdf

Baxter, L. A., \& Pederson, J. R. (2013). Perceived and ideal family communication patterns and family satisfaction for parents and their college-aged children. The Journal of Family Communication, 13, 132-149. https://doi.org/10.1080/15267431.2013.768250

Beebe, T. J., Harrison, P. A., Mcrae, J. A. Jr., Anderson, R. E., \& Fulkerson, J. A. (1998). An evaluation of computer-assisted self-interviews in a school setting. Public Opinion Quarterly, 62(4), 623-632. https://doi.org/10.1086/297863 
Bostwick, E. N., \& Johnson, A. J. (2018). Family secrets: The roles of family communication patterns and conflict styles between parents and young adult children. Communication Reports, 31(2), 91-102. https://doi.org/10.1080/08934215.2017.1380209

Brewer, J. T., \& Lubienski, C. (2017). Homeschooling in the United States: Examining the rationales for individualizing education. Pro-Posições, 28(2), 21-38. https://doi.org/10.1590/1980-6248-2016-0040

Brown, J. (1997). Parents rationale for homeschooling: A qualitative study. [Unpublished master's thesis]. Youngstown State University.

Brown-Wright, G. (2011). Student-centered learning in higher education. International Journal of Teaching and Learning in Higher Education, 23(3), 92-97. http://www.isetl.org/ijtlhe/

Buchanan, C. M., Maccoby, E. E., \& Dornbush, S. M. (1991). Caught between parents: Adolescents' experience in divorced homes. Child Development, 62(5), 1008-1029. https://doi.org/10.2307/1131149

Burns, M. E., \& Pearson, J. C. (2011). An exploration of family communication environment, everyday talk, and family satisfaction. Communication Studies, 62(2), 171-185. https://doi/org/10.1080/10510974.2010.523507

Cairns, R. B. (1977). Beyond social attachment: The dynamics of interactional development. In T. Alloway, P. Pliner, \& L. Krames (Eds.), Attachment behavior: Advances in the study of communication and affect (Vol. 3). Springer. https://doi.org/10.1007/978-1-46134187-1_1

Collom, E. (2005). The ins and outs of homeschooling: The detriments of parental motivations and student achievement. Education and Urban Society, 37(3), 307-335. https://doi.org/10.1177/00131124504274190 
Elgström, O., \& Hellsenius, M. (2011). Curriculum debate and policy change. Journal of Curriculum Studies, 43(6), 717-738. https://doi.org/10.1080/00220272.2011.584562

Endress, S. L. (2011). An analysis of Illinois' practice of non-purposeful homeschooling: Policy recommendations for Illinois lawmakers. [Unpublished doctoral dissertation]. Illinois State University.

Fingerman, K. L. (1995) Aging mothers' and their adult daughters' perceptions of conflict behaviors. Psychology and Aging. 10(4), 639-649. https://doi.org/10.1037/08827974.10.4.639

Fletcher, G. J. O. (1993). Cognition in close relationships. New Zealand Journal of Psychology. 22(2), 69-81. https://doi.org/110.4324/9780203772027

Fredholm, A. (2017). Reconsidering school politics: Educational controversies in Sweden. The Curriculum Journal, 28(1), 5-21. https://doi.org/10.1080/09585176.2016.1191361

Garcia, B., \& Conway, B. (2019). Appropriate processing time: Valuing process over product. European Journal of Educational Sciences, 6(3), 1-15. https://doi.org/10.19044/ejes/v6mo3a1

Garrett, T. (2008) Student-centered and teacher-centered classroom management: A case study of three elementary teachers. Journal of Classroom Interaction, 43(1), 34-47. https://doi:10.1080/00220671.2019.1645085

Givertz, M., \& Segrin, C. (2014). The association between overinvolved parenting and young adults' self-efficacy, psychological entitlement, and family communication. Communication Research, 41(8), 1111-1136. https://doi:10.1177/0093650212456392 
Golish, T. D. (2000). Changes in closeness between adult children and parents: A turning point analysis. Communication Reports, 13(2), 79-97. https://doi.org/10.1080/08934210009367727

Goodyear, V., \& Dudley, D. (2015). I'm a facilitator of learning! Understanding what teachers and students do within student-centered physical education models. Quest, 67(3), 274289. https://doi.org/10.1080/00336297.2015.1051236

Guan, X., \& Li, X. (2017). A cross-cultural examination of family communication patterns, parent-child closeness, and conflict styles in the United States, China, and Saudi Arabia. Journal of Family Communication, 17(3), 223-237. https://doi.org/10.1080/15267431.2017.1293062

Haber-Curan, P. C., \& Tillapaugh, D. W. (2015). Student-centered transformative learning in leadership education: An examination of the teaching and learning process. Journal of Transformative Education, 13(1), 65-84. https://doi.org/10.1177/1541346614559947

Hammonds, J. R. (2015). A model of privacy control: Examining the criteria that predict emerging adults' likelihood to reveal private information to their parents. Western Journal of Communication, 79(5), 591-613. https://doi.org/10.1080/10570314.2015.108311

Hendrick, S. S. (1988). A generic measure of relationship satisfaction. Journal of Marriage and the Family, 50, 93-98. https://doi.org/10.2307/352430

Home-School Legal Defense Association. (2020). Homeschool laws by state. https://hslda.org/legal 
Horstman, H. K., Schrodt, P., Warner, B., Koerner, A., Maliski, R., Hays, A., \& Colaner, C. W. (2018). Expanding the conceptual and empirical boundaries of family communication patterns: The development and validation of an expanded conformity orientation scale. Communication Monographs, 85, 157-180. https://doi.org/10.1080/03637751.2018.1428354

Hunt, M. W. (2019, February). Going "gradeless” in a CTE classroom. Techniques. https://www.acteonline.org/

Illinois Statute 105 ILCS S 5/26-1.

Kelly, L., Keaton, J. A., Finch, C., Duarte, I. B., Hoffman, P., \& Michels, M. M. (2002). Family communication patterns and the development of reticence. Communication Education, 51(2), 202-209. https://doi.org/10.1080/03634520216506

Kelly, L., Duran, R. L., \& Miller-Ott, A. E. (2017). Helicopter parenting and cell-phone contact between parents and children in college. Southern Communication Journal, 82(2), 102114. https://dx.doi.org/10.1080/1041794X.2017.1310286

Love, P. G., \& Guthrie, V. L. (1999). King and Kitchener's reflective judgement model. New Directions for Student Services, 1999(88), 41-51. https://doi.org/10.1002/ss.8804

Koerner, A. F., \& Fitzpatrick, M. A. (2002a). Toward a theory of family communication. Communication Theory, 12(1), 70-91. https://doi.org/10.1111/j.1468-2885.2002.tb00260

Koerner, A. F., \& Fitzpatrick, M. A. (2002b). Understanding family communication patterns and family functioning: The roles of conversation orientation and conformity orientation. In W. B. Gudyknust (Ed.), Communication yearbook 26 (pp. 36-68). Lawrence Erlbaum Associates. https://doi.org/10.4324/9780203848166 
Koerner, A. F., \& Fitzpatrick, M. A. (2006). Family communication patterns theory: A social cognitive approach. In D. O. Braithwaite \& L. A. Baxter (Eds.), Engaging theories in family communication: Multiple perspectives (pp. 50-65). Sage.

Koerner, A. F., \& Schrodt, P. (2014). An introduction to the special issue on family communication patterns theory. Journal of Family Communication, 14, 1-15. https://doi.org/10.1080/15267431.2013.857328

Koesten, J., \& Anderson, K. (2004). Exploring the influence of family communication patterns, cognitive complexity, and interpersonal competence on adolescent risk behaviors. Journal of Family Communication, 4(2), 99-121. https://doi.org/10.1207/s15327698jfc0402_2

Larsson, J., Lörfdahl, A., \& Preito, H. P. (2010). Rerouting: Discipline, assessment and performativity in contemporary Swedish educational discourse. Education Inquiry, 1(3), 17-195. http://dx.doi.org/10.3402/edui.v1i3.21941

Ledbetter, A. M. (2009). Family communication patterns and relational maintenance behavior: Direct and mediated associations with friendship closeness. Human Communication Research, 35, 130-147. https://doi.org/10.1111/j.1468-2958.2008.01341.x

Ledbetter, A. M., \& Beck, S. J. (2014). A theoretical comparison of relational maintenance and closeness as mediators of family communication patterns in parent-child relationships. Journal of Family Communication, 14(3), 230-252. https://doi:10.1080/15267431.2014.908196

Lubienski, C. Puckett, T., \& Brewer, J. T. (2013) Does homeschooling work? A critique of the empirical claims and agenda of advocacy organizations. Peabody Journal of Education 88(2), 378-392. https://doi.org/10.1080/0161956X.2013.798516 
Padilla, V. E. (2020). Organizations that support home-school: An exploratory study of communication with home-school parents and students [Unpublished paper]. Illinois State University, Illinois.

Ray, B. (2020). Research facts on homeschooling, homeschool fast facts. National Home Education Research Institute. https://www.nheri.org/research-facts-on-homeschooling/

Ritchie, L. D., \& Fitzpatrick, M. A. (1990). Family communication patterns: measuring intrapersonal perceptions of interpersonal relationships. Communication Research, 17(4), 523-544. https://doi.org/10.1177/009365090017004007

Romanowski, M. (2006). Revisiting the common myths about homeschooling. The Clearing House, 79(3), 125-129. https://doi.org/10.3200/tchs.79.3.125-129

Schrodt, P. (2009). Family strength and satisfaction as functions of family communication environments. Communication Quarterly, 52(2), 171-186. https://doi.org/10.1080/01463370902881650

Sinhaneti, K., \& Kyaw, E. K. (2012). A study of role of rote learning in vocabulary learning strategies of Burmese students. US-China Education Review, 12, 987-1005. http://www.davidpublisher.org/

Shebib, S. J. (2020). The apple doesn't fall far from the tree: Emerging adult children responses to parents during conflict interaction [Doctoral dissertation, Michigan State University]. ProQuest Dissertations Publishing.

Stein, C. H., Osborn, L. A., \& Greenberg, S. C. (2016). Understanding young adults' reports of contact with their parents in a digital world: Phycological and familial relationship factors. Springer Science and Business Media, 25, 1802-1814. https://doi.org/10.1007/s10826-016-0366-0 
Strage, A. A. (1998). Family context variables and the development of self-regulation in college students. Adolescence, 33(129), 17-31. https://www.questia.com/library/p4790/adolescence

Thomas, J. (2016). Learning from homeschooling routines. Journal of Research on Christian Education, 25(3), 233-250. https://doi.org/10.1080/10656219.2016.1237910

Wang, B., Taylor, L., \& Sun, Q. (2018). Families that play together stay together: Investigating family bonding through video games. New Media \& Society, 20(11), 4074-4094. https://doi.org/10.1177/1461444818767667 


\section{APPENDIX: SURVEY INSTRUMENT}

\section{Sorting Questions}

1) Did you participate as a student or parent/instructor in homeschooling for at least one year?

- Yes (please continue with the survey)

- No (please exit the survey)

2) Were you a homeschool student or homeschool parent? (Routes to appropriate survey)

- Homeschool student

- Homeschool parent/instructor

Note for parents: Please keep in mind the one child when answering these questions. Please keep that same child in mind throughout the survey.

\section{Homeschooling Instructional Approach Scale}

I would like to learn more about the way instruction was provided in your homeschool setting. Please use the scale to indicate your agreement with the following statements.
$\stackrel{1}{\text { Strongly }}$
$\stackrel{2}{\stackrel{2}{\text { Disagree }}}$
$\stackrel{3}{\text { Neutral }}$
$\stackrel{4}{\text { Agree }}$
$\underline{5}$
Disagree

1. During homeschool, I (my child) had a say in the coursework I (they) studied.

2. I (My child) received a lot of "hands-on" and discovery learning.

3. I (my child) had a great deal of input in my (their) homeschool education.

4. The homeschool environment was flexible enough to meet my needs (my child's needs).

5. I (my child) felt concerns I (they) had regarding my (their) education were considered and discussed.

6. During lessons, we discussed material and applied it to real life/world experiences.

7. I (My child) worked independently at my (their) own pace.

8. My parent (I) played an active role in my (their) learning process.

9. My parent (I) made sure I fully understood before moving onto a new lesson.

10. My day (Their day) consisted of my parent (me) directly providing instruction.

11. My parent (I) helped me (them) with difficult assignments and concepts.

12. My parent (I) regularly monitored my (their) progress through assessment.

13. My parent (I) was very involved in my (their) school work.

14. During lessons, my parent (I) was engaged in my (their) learning.

15. During homeschool, my parent and I (my child and I) discussed my (their) interests and planned lessons accordingly.

16. In our homeschool, my parent and I (my child and I) both understood the expectations for school work.

17. In homeschool, my parent (I) acted as a guide during lessons when I (they) required it. 
18. My parent and I (My child and I) engaged in frequent communication regarding my schoolwork.

19. During homeschool, my parent (I) took pride in my (their) school work and projects.

20. During homeschool, my parent (I) provided regular feedback on my (their) work.

Items 1-10 averaged for learner-centered instructional type.

Items 11-20 averaged for traditional instructional type.

\section{Revised Family Communication Patterns Scale (Conversation Orientation)}

Directions: I would like to learn more about how your family communicated during the time homeschooling took place. Please use this scale to indicate your agreement with the following statements.

Note: Statements will be worded appropriately for participant (parent/child)

\begin{tabular}{|c|c|c|c|c|c|c|}
\hline $\begin{array}{l}\underline{1} \\
\text { Strongly } \\
\text { Disagree }\end{array}$ & $\begin{array}{c}\stackrel{2}{\text { Somewhat }} \\
\text { Disagree }\end{array}$ & $\stackrel{3}{\text { Disagree }}$ & $\begin{array}{c}\stackrel{4}{\underline{T}} \\
\text { Neither } \\
\text { Agree nor } \\
\text { Disagree }\end{array}$ & $\stackrel{5}{\text { Agree }}$ & $\begin{array}{c}\underline{6} \\
\text { Somewhat } \\
\text { Agree }\end{array}$ & $\begin{array}{c}\underline{7} \\
\text { Strongly } \\
\text { Agree }\end{array}$ \\
\hline
\end{tabular}

1. In our family we often talked about topics like politics and religion where some people disagreed with others.

2. My parents (I) often said something like "Every member of the family should have some say in family decisions."

3. My parents (I) often asked my (my child's) opinion when the family is talking about something.

4. My parents (I) encouraged me (my child) to challenge their (my) ideas and beliefs.

5. My parents (I) often said something like "You should always look at both sides of an issue."

6. I (My child) usually told my parents (me) what I was (they were) thinking about things.

7. I (My child) could tell my parents (me) almost anything.

8. In our family we often talked about our feelings and emotions.

9. My parents (My child) and I often had long, relaxed conversations about nothing in particular.

10. I (think my child) really enjoyed talking with my parents (me), even when we disagreed.

11. My parents (I) encouraged me (my child) to express my feelings.

12. My parents (I) tended to be very open about their (my) emotions.

13. We often talked as a family about things we had done during the day.

14. In our family, we often talked about our plans and hopes for the future.

15. My parents (I) liked to hear my (my child's) opinion, even when I didn't agree with them.

Items 1 - 15 averaged for conversation orientation subscale from RFCP. 


\section{Expanded Conformity Orientation Scale}

Directions: I would like to learn more about how your family communicated during the time homeschooling took place. Please use this scale to indicate your agreement with the following statements.

Note: Statements will be worded appropriately for participant (parent/child)

\begin{tabular}{|c|c|c|c|c|c|c|}
\hline $\begin{array}{l}\underline{1} \\
\text { Strongly } \\
\text { Disagree }\end{array}$ & $\begin{array}{c}\underline{2} \\
\text { Somewhat } \\
\text { Disagree }\end{array}$ & $\stackrel{3}{\text { Disagree }}$ & $\begin{array}{l}\stackrel{4}{\text { Neither }} \\
\text { Agree nor } \\
\text { Disaoree }\end{array}$ & $\stackrel{5}{\text { Agree }}$ & $\begin{array}{c}\underline{6} \\
\text { Somewhat } \\
\text { Agree }\end{array}$ & $\begin{array}{c}\underline{7} \\
\text { Strongly } \\
\text { Agree }\end{array}$ \\
\hline
\end{tabular}

1. My parents (I) expected us to respect our (their) elders.

2. In our home, I (my child) was expected to speak respectfully to my parents (me).

3. My parents (I) had clear expectations about how a child was to behave.

4. When I (my child) was at home, I (they) was (were) expected to obey my parents' (my) rules.

5. My parents (I) insisted that I (my child) respect those who have been placed in positions of authority.

6. My parents (I) emphasized certain attitudes that they (I) wanted the children in our family to adopt.

7. In our home, my parents (the parents) had the last word.

8. My parents (I) expected me (my child) to trust their (my) judgment on important matters.

9. I (my child) was expected to follow my parents' (my) wishes.

10. My parents (I) felt it is important to be the boss.

11. My parents (I) became irritated with my (my child's) views if they were different from their (my) views.

12. My parents (I) tried to persuade me (my child) to view things the way they (I) saw them.

13. My parents (I) said things like "You'll know better when you grow up."

14. My parents (I) said things like "You may not understand why we are doing this right now, but someday you will."

15. My parents (I) said things like "My ideas are right and you should not question them."

16. In my family, family members were expected to hold similar values.

17. I (My child) was expected to adopt my parents' (my) views.

18. My parents (I) encouraged me (my child) to adopt their (my) values.

19. Our family had a particular way of seeing the world.

20. I (My child may have) felt pressure to adopt my parents' (my) views.

21. I (My child) was expected to challenge my parent's (my) beliefs.

22. In our home, we were (my child was) allowed to question my parents' (my) authority.

23. My parents (I) encouraged open disagreement.

24. In our home, we were (my child was) encouraged to question my parents' (my) authority.

Items 1-24 averaged for conformity orientation subscale from ECOS.

Recoded Items 21-24. 


\section{Modified Relational Satisfaction Assessment Scale}

Directions: Please use the following scales to answer these questions about your satisfaction with the parent that homeschooled you/ child that you homeschooled.

1. How well does this parent/child meet your needs?

$1=$ Not at all, $4=$ Moderately, $7=$ Very well

2. In general, how satisfied are you with your relationship with this parent/child?

$1=$ Very low satisfaction, $4=$ Moderate satisfaction, $7=$ Very high satisfaction

3. How good is your relationship with this parent/child compared to most?

$1=$ Very bad, $4=$ About average, $7=$ Very good

4. How much do you love this parent/child?

$1=$ Not at all, $4=$ Moderately, $7=$ Very much

5. How many problems are there in your relationship with this parent/child?*

$1=$ Lots of problems, $4=$ Moderate problems, $7=$ No problems

Items 1-5 (but recoding item 5) averaged for relational satisfaction.

\section{Modified Relational Closeness Scale}

For the purpose of this study. Please answer the following questions while keeping the parent that provided / child that received the majority of the homeschool instruction. Please answer the following on a scale of 1-5.
$\stackrel{1}{\text { Always }}$
$\stackrel{2}{\underline{2}}$
$\stackrel{3}{\text { Neutral }}$
Sometimes
$\underline{5}$
Never

1. Do you talk openly with your parent/child?

2. Do you have to be careful about what you say to your parent/child?

3. Do you feel comfortable admitting doubts to your parent/child?

4. Is your parent/child interested in talking when you want to talk?

5 . Does your parent/child frequently express affection for you?

6 . Does your parent/child know what you are really like?

7. Do you feel close to this parent/child?

8. Would your parent/child help you if you had a problem?

9. If you needed money (your child), do you feel comfortable (do they) asking them (you)?

10. Is this parent/child interested in the things you do?

Item 2 recoded. 


\section{Miscellaneous Questions}

1. How would you rate homeschool prepared you/your child for the future? (0-100)

$0=$ not at all, $50=$ neutral, $100=$ very much

2. Do you think homeschool improved your relationship with your parent/child? (0-100)

$0=$ not at all, $50=$ neutral, $100=$ very much

\section{Demographics and Background}

All Participants

1. What is your age? (Number slider) 18-100

2. What is your biological sex? (Multiple choice)

- Male

-Female

3. What is the biological sex of the primary child (parent) receiving (providing) instruction?

(Multiple choice)

- Male

- Female

4. What is your race/ethnicity? (Multiple choice)

- White

- Black or African American

- American Indian and Alaska Native

- Asian

- Native Hawaiian or Other Pacific Islander

- Bi-racial/Mixed

- Other

5. How long did your homeschool experience last? (Slider of years)

$-1-15$

6. Did homeschool occur during elementary, middle school or high school? (Check all that apply)

- Elementary

- Middle School

- High School

7. How long since you participated in / taught homeschool? (Slider of years)

$-0-50$

8. Did you participate in a homeschool cooperative? (Multiple choice)

- Yes, all the time

- Yes, some of the time.

- No, not at all. 